\title{
Dual Nicotinic Acetylcholine Receptor 42 Antagonists/7 Agonists: Synthesis, Docking Studies, and Pharmacological Evaluation of Tetrahydroisoquinolines and Tetrahydroisoquinolinium Salts
}

Crestey, François; Jensen, Anders A; Soerensen, Christian; Magnus, Charlotte Busk; Andreasen, Jesper T; Peters, Günther H.J.; Kristensen, Jesper L.

Published in:

Journal of Medicinal Chemistry

Link to article, DOI:

10.1021/acs.jmedchem.7b01895

Publication date:

2018

Document Version

Peer reviewed version

Link back to DTU Orbit

Citation (APA):

Crestey, F., Jensen, A. A., Soerensen, C., Magnus, C. B., Andreasen, J. T., Peters, G. H. J., \& Kristensen, J. L. (2018). Dual Nicotinic Acetylcholine Receptor 42 Antagonists/7 Agonists: Synthesis, Docking Studies, and Pharmacological Evaluation of Tetrahydroisoquinolines and Tetrahydroisoquinolinium Salts. Journal of Medicinal Chemistry, 61(4), 1719-1729. https://doi.org/10.1021/acs.jmedchem.7b01895

\section{General rights}

Copyright and moral rights for the publications made accessible in the public portal are retained by the authors and/or other copyright owners and it is a condition of accessing publications that users recognise and abide by the legal requirements associated with these rights.

- Users may download and print one copy of any publication from the public portal for the purpose of private study or research.

- You may not further distribute the material or use it for any profit-making activity or commercial gain

- You may freely distribute the URL identifying the publication in the public portal 


\title{
Dual Nicotinic Acetylcholine Receptors $\alpha 4 \beta 2$ Antagonists/ $\alpha 7$ Agonists: Synthesis, Docking Studies and Pharmacological Evaluation of Tetrahydroisoquinolines and Tetrahydroisoquinolinium Salts
}

\author{
François Crestey, ${ }^{\dagger, \S}$ Anders A. Jensen, ${ }^{\dagger, \S}$ Christian Soerensen, ${ }^{\ddagger}$ Charlotte Busk Magnus, ${ }^{\dagger,}$ Jesper T. \\ Andreasen, ${ }^{\dagger}$ Günther H. J. Peters ${ }^{\ddagger}$ and Jesper L. Kristensen ${ }^{*}{ }^{\dagger}$
}

${ }^{\dagger}$ Department of Drug Design and Pharmacology, Faculty of Health and Medical Sciences, University of Copenhagen, Universitetsparken 2, 2100 Copenhagen, Denmark

${ }^{\ddagger}$ Department of Chemistry, Technical University of Denmark, Kemitorvet 207, 2800 Kongens Lyngby, Denmark

ABSTRACT: We describe the synthesis of tetrahydroisoquinolines and tetrahydroisoquinolinium salts together with their pharmacological properties at various nicotinic acetylcholine receptors. In general the compounds were $\alpha 4 \beta 2$ nAChR antagonists, with the tetrahydroisoquinolinium salts being more portent than the parent tetrahydroisoquinoline derivatives. The most potent $\alpha 4 \beta 2$ antagonist $6 \mathbf{c}$, exhibited submicromolar binding $\mathrm{K}_{\mathrm{i}}$ and functional $\mathrm{IC}_{50}$ values and high selectivity for this receptor over the $\alpha 4 \beta 4$ and $\alpha 3 \beta 4$ nAChRs. Whereas the (S)-6c enantiomer was essentially inactive at $\alpha 4 \beta 2$, $(R)$ 6c was a slightly more potent antagonist than the reference $\beta 2-n A C h R$ antagonist $\mathrm{DH} \beta \mathrm{E}$. The observation that the $\alpha 4 \beta 2$ activity resided exclusively in the $(R)$-enantiomer was in full agreement with docking studies. Several of tetrahydroisoquinolinium salts also displayed agonist activity at the $\alpha 7$ nAChR. Preliminary in vivo evaluation revealed antidepressant-like effects of both $(R)-5 \mathbf{c}$ and $(R)-\mathbf{6 c}$ in the mouse forced swim test supporting the therapeutic potential of $\alpha 4 \beta 2 \mathrm{nAChR}$ antagonists for this indication. 
Keywords: nAChRs, dual $\alpha 4 \beta 2$ antagonist/ $\alpha 7$ agonist, tetrahydroisoquinolines, quaternary ammonium salts, chiral resolution.

\section{INTRODUCTION}

The nicotinic acetylcholine receptors (nAChRs), a heterogeneous family of ligand-gated ion channels widely distributed throughout the peripheral and central nervous systems, are involved in a broad range of psychiatric and neurodegenerative disorders such as schizophrenia, attention deficit hyperactivity disorder, depression, Alzheimer's and Parkinson’s diseases, pain and substance abuse. ${ }^{1-4}$ Considerable efforts have been put into the design of agonists (based on scaffolds such as nicotine, varenicline, cytisine and epibatidine) as well as positive allosteric modulators targeting the neuronal nAChRs. ${ }^{5-9}$ In comparison, antagonists are far less studied, despite their substantial therapeutic potential. ${ }^{10-20}$ Most of the available nAChR antagonists are natural products such as methyllycaconitine (MLA), $\alpha-$ bungarotoxin, ibogaine, d-tubocurarine, $\alpha$-conotoxins and dihydro- $\beta$-erythroidine (DH $\beta E)$, the latter being a widely used selective antagonist of $\beta 2$-containing heteromeric nAChRs and a semisynthetic member of the Erythrina alkaloid family. ${ }^{21,22}$ We recently reported the design, synthesis and pharmacological evaluation of 21 analogs of aromatic Erythrina alkaloids as nAChR antagonists and found that the structurally simple tetrahydroisoquinoline $\mathbf{1}$ (also known as $O$-methylcorypalline) ) $^{23,24}$ displayed submicromolar binding affinity at the $\alpha 4 \beta 2$ nAChR and more than 300-fold binding selectivity over the $\alpha 4 \beta 4, \alpha 3 \beta 4$ and $\alpha 7$ subtypes (see Figure $1 \mathrm{~A}$ ). ${ }^{25}$

Ligands containing quaternary nitrogens have previously been shown to possess high activity at the nAChR. ${ }^{27-30}$ For example, several known nAChR antagonists and neuromuscular blocking agents are mono- and bis-quaternary ammonium derivatives, ${ }^{31}$ and Crooks and co-workers have investigated $N$ substituted nicotine analogs and bis-azaaromatic quaternary ammonium ligands at the $\alpha 4 \beta 2$ and $\alpha 7$

receptors. ${ }^{32-36}$ Furthermore, introduction of a methyl group in cytisine (which provides caulophylline) has been shown to dramatically reduce its affinity at the $\alpha 4 \beta 2$ receptor, while a second $N$-methylation 
restores the affinity. ${ }^{37}$ Finally, the nAChR antagonism exhibited by a broad range of synthetic and natural quaternary derivatives of curare-like alkaloids has been described. ${ }^{38}$

In view of the promising properties of $O$-methylcorypalline (1) in our previous study, ${ }^{25}$ we decided to pursue a series of quaternary ammonium salts (series 2) based on this scaffold where the length and the size of the $N$-substituent was varied. Based on their pharmacological properties, two subsequent series of tetrahydroisoquinolines $\mathbf{3}$ and $\mathbf{5}$ were targeted to provide $N$-methyl tetrahydroisoquinolinium iodides 4 and 6, respectively (see Figure 1B).

\section{RESULTS AND DISCUSSION}

Synthetic chemistry. As depicted in Scheme 1, treatment of tetrahydroisoquinoline 1 with the appropriate alkyl or benzyl halides led to the corresponding quaternary ammonium salts 2a-e in 6796\% yield. $N$-Methyl tetrahydroisoquinolinium iodides $\mathbf{4 a - f}$ and $\mathbf{6 a - g}$ were obtained in 63-96\% yield after reaction of the corresponding tetrahydroisoquinolines $\mathbf{3 a}-\mathbf{f}$ and $\mathbf{5 a} \mathbf{a} \mathbf{g}$ with methyl iodide in dry acetone. Besides, racemic ligands $\mathbf{5 c}$ and $\mathbf{5 d}$ were obtained via a three-step protocol as depicted in Scheme 2. ${ }^{39}$ First, phenethylamines $7 \mathbf{a}$-b were heated in neat $\gamma$-butyrolactone at $150{ }^{\circ} \mathrm{C}$ for 15 min under MW conditions providing amides $8 \mathbf{a}-\mathbf{b}$ which cyclized upon treatment with $\mathrm{POCl}_{3}$ at $150{ }^{\circ} \mathrm{C}$ for 15 min once again under MW conditions. Subsequent reduction of the intermediate iminium salt with $\mathrm{NaBH}_{4}$ gave tetrahydroisoquinolines $5 \mathbf{c}$ and $5 \mathbf{d}$ in $39 \%$ and $21 \%$ overall yield, respectively. ${ }^{40}$

The two enantiomerically pure compounds $(R)-\mathbf{5 d}$ and $(S)-\mathbf{5 d}$ which are also known as $(R)-(+)$-crispine A and (S)-(-)-crispine A, respectively, as well as (S)-5c and (R)-5c were resolved via separation on chiral HPLC. ${ }^{41,42}$ The absolute configurations of (S)-5c and (R)-5c (and consequently (S)-6c and $\left.(R)-6 \mathbf{c}\right)$ were established as detailed in the Supporting Information. As shown in Scheme 2, (S)-5c, $(R)-5 \mathbf{c},(S)-$ $\mathbf{5 d}$ and $(R)-\mathbf{5 d}$ were quaternized using methyl iodide in acetone to provide $(S)-\mathbf{6 c},(R)-\mathbf{6 c},(S)-\mathbf{6 d}$ and (R)-6d in 60\%, 54\%, 42\% and 44\% yield, respectively.

Computational chemistry: A docking study of the aforementioned ligands was performed using Glide $^{43}$ in extra precision mode based on the recently published X-ray structure of the human $\alpha 4 \beta 2$ 
$\mathrm{nAChR}{ }^{44}$ with a critical water molecule modelled into the binding site. ${ }^{45}$ Figure 2 shows the spacial limitations of the binding pocket with bicyclic derivatives $\mathbf{2 a - c}$. Thus, the quaternization of the amine, responsible for important $\pi$-cation interactions, with substituents larger than a methyl backbone leads to serious steric clashes which are substantiated by the affinities of the abovementioned ligands. Interestingly, the chiral carbon atom next to the amine showed consistent difference as there was a clear tendency of ligands with a $R$-configuration to yield higher binding affinity originating from $\pi$-cation interactions between the charged ligand nitrogen and receptor residues as well as a hydrogen-bond between the moiety derived from a catechol function and the water molecule. The specific binding of the ligands was mediated by the two mentioned pharmacophores where the hydrogen-bond acceptor moiety was often the differentiator between the two enantiomers, as the ligands tended to twist which resulted in an increased hydrogen bond acceptor-donor distance. As shown in Figure 3A, the position of the amine moiety of (R)-6c (colored in dark green) and (S)-6c (colored in purple) seems to be regulated by the absolute configuration in order to obtain optimal fit into the binding site. This is confirmed by the poses of (R)-6c and (S)-6c depicted in Figure 3B. Although both ligands appear very uniform, small changes regarding the amine position are critical for the affinity and the number of interactions.

With a coefficient of determination of 0.58 between the docking scores and the in vitro data of the enantiopure ligands, the model correlates well with the experimentally determined affinities. This was further supported by re-docking nicotine into the binding site yielding a root-mean-square deviation value of $0.66 \AA$. The generated poses indicated that the position of the amine moiety was essential as it entailed 2-4 $\pi$-cation interactions to receptor residues depending on the compound as expected based on previous studies (for more details see the Supporting Information). ${ }^{46}$

In vitro evaluation: The binding properties of the compounds were determined using membranes from the stable r $\alpha 3 \beta 4-$, r $\alpha 4 \beta 4$ - and r $\alpha 4 \beta 2-H E K 293$ cell lines in a $\left[{ }^{3} \mathrm{H}\right]$ epibatidine binding assay. The

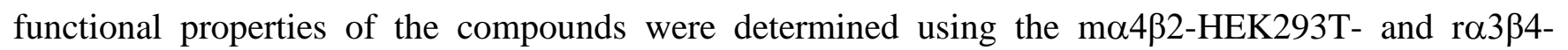
HEK293-cell lines in the FLIPR Membrane Potential Blue (FMP) assay essentially as previously 
described, ${ }^{16,18,25,26}$ whereas the functional characterization of selected ligands at the human $\alpha 7 \mathrm{nAChR}$ was performed at the stable h $\alpha 7^{\text {Ric-3/NACHO}}-$ HEK293 cell line in the $\mathrm{Ca}^{2+} /$ Fluo-4 assay in the presence of the $\alpha 7 \mathrm{nAChR}$ PAM PNU-120596 (3 $\mu \mathrm{M})$. (S)-Nicotine (EC $\left.{ }_{70}-\mathrm{EC}_{90}\right)$ was used as agonist in the antagonist experiments at m $\alpha 4 \beta 2$ and r $\alpha 3 \beta 4$ in the FMP assay, and acetylcholine (EC ${ }_{70}$ EC $_{90}$ ) was used as agonist in the antagonist experiments at ho7 in the $\mathrm{Ca}^{2+} /$ Fluo- 4 assay. All ligands were tested both as agonists and antagonists.

Binding and functional properties of the analogs at the $\alpha 4 \beta 2, \alpha 4 \beta 4$ and $\alpha 3 \beta 4 n A C h R s$. The methyl tetrahydroisoquinolinium derivative 2a was found to be equipotent with the parent compound as an $\alpha 4 \beta 2$ nAChR antagonist. The $N$-ethylation of $O$-methylcorypalline (1) which provided derivative $\mathbf{2 b}$ was also well tolerated although its affinity at the $\alpha 4 \beta 2$ nAChR was about 10 -fold lower when compared to the methyl derivative 2a. A further increase in the bulk on the nitrogen when growing through propyl, allyl and benzyl led to decreases in both the affinities and antagonistic potencies of the analogs at the $\alpha 4 \beta 2 \mathrm{nAChR}$ (Table 1) as suggested by the docking studies. All of these compounds displayed negligible binding affinities at the $\alpha 4 \beta 4$ and $\alpha 3 \beta 4$ nAChRs. In view of this, we proceeded with the quaternization of structurally related scaffolds with $N$-methyl groups. Derivatives $3 \mathbf{d}$ and $\mathbf{4 d}$ displayed no significant binding affinity at any of the tested subtypes, suggesting that substitution on C1 is detrimental to nAChR activity, at least when a rather bulky substituent is introduced in this position. ${ }^{25}$ In contrast, the binding affinities at $\alpha 4 \beta 2$ were increased for all bicyclic derivatives with the presence of the quaternary nitrogen. Overall, the tetrahydroisoquinolinium salts 4 exhibited $\sim 5$-fold higher binding affinities at $\alpha 4 \beta 2$ than the parent tetrahydroisoquinolines 3 , with all of these analogs displaying negligible activity at the $\alpha 4 \beta 4$ and $\alpha 3 \beta 4$ nAChRs (Table 1, Figure 4A). For example, 4c displayed a similar $\mathrm{K}_{\mathrm{i}}$ value at the $\alpha 4 \beta 2 \mathrm{nAChR}(0.38 \mu \mathrm{M})$ as that displayed by $\mathrm{DH} \beta \mathrm{E}$ and $~ 80-$ and 130-fold binding selectivity for $\alpha 4 \beta 2$ over $\alpha 4 \beta 4$ and $\alpha 3 \beta 4$ nAChRs, respectively. In contrast, the IC 50 values displayed by the tetrahydroisoquinolinium compounds compared to their respective tetrahydroisoquinolines at the $\alpha 4 \beta 2 \mathrm{nAChR}$ in the FMP assay were largely comparable, and thus the 
introduction of the methyl group on the nitrogen only seemed to slightly increase the functional inhibitory potencies of some of these analogs. We propose that this difference in the relative binding affinities and antagonist potencies of the bicyclic derivatives $\mathbf{3}$ and $\mathbf{4}$ could arise from the fact that the measurement of binding affinities and functional inhibitory potencies most likely are performed at different $\alpha 4 \beta 2$ nAChR conformations. In terms of understanding of the SAR of these compounds, no clear conclusions with respect to the substitution pattern on the phenyl ring of the tested bicyclic ligands could be extracted from these series.

Interestingly, the increase in $\alpha 4 \beta 2$ binding affinity brought on by quaternization of the nitrogen with a methyl side chain was reproduced when moving from the bicyclic scaffold to the tricyclic ring system, albeit to a smaller extent than for the bicyclic analogs (Table 2). Thus, quaternization of 5a-g generally led to ligands (6a-g) exhibiting higher binding affinities at the $\alpha 4 \beta 2$ nAChR, and this was also generally accompanied by weak binding affinities to the $\alpha 4 \beta 4$ and $\alpha 3 \beta 4$ nAChRs (Table 2, Figure 4A). For example, the tetrahydroisoquinolinium derivative 6c displayed a 5-fold lower $\mathrm{K}_{\mathrm{i}}$ value $(0.14 \mu \mathrm{M})$ than $\mathrm{DH} \beta \mathrm{E}$ at $\alpha 4 \beta 2$ and displayed the highest degree of binding selectivity for $\alpha 4 \beta 2$ over the $\alpha 4 \beta 4$ and $\alpha 3 \beta 4$ nAChRs (360- and 210-fold, respectively) of the analogs in the series. Compounds 5e and 6e constituted interesting outliers from this overall $\alpha 4 \beta 2$ selectivity, as both ligands displayed comparable binding affinities to the $\alpha 4 \beta 2$ and $\alpha 4 \beta 4$ nAChRs and considerably weaker binding affinities to the $\alpha 3 \beta 4$ subtype. When tested at the $\alpha 4 \beta 2$ nAChR in the FMP assay, several of the tetrahydroisoquinolinium analogs displayed significantly higher antagonist potencies than the corresponding tetrahydroisoquinoline analogs, the $\mathrm{IC}_{50}$ values of $\mathbf{6 a}, \mathbf{6 b}, \mathbf{6 c}$ and $\mathbf{6 e}$ at the $\alpha 4 \beta 2 \mathrm{nAChR}$ being $5-10$ fold lower than those of $\mathbf{5 a}, \mathbf{5 b}, \mathbf{5} \mathbf{c}$ and $\mathbf{5 e}$, respectively (Table 2, Figure $4 \mathrm{~A}$ ). With a functional IC $_{50}$ value of $0.52 \mu \mathrm{M}$, 6c was the most potent $\alpha 4 \beta 2 \mathrm{nAChR}$ antagonist emerging from this series, and just as the other derivatives in this study 6 c displayed negligible activity at the $\alpha 3 \beta 4$ nAChR in the FMP assay. Inspired by the findings in the computational chemistry investigation and in a previous study on a $\alpha 4 \beta 2$ selective bridged-nicotine antagonist, ${ }^{18}$ we next investigated whether the two sets of enantiomers of $5 \mathbf{c}$ 
and 5d, i.e. ligands $(S)-5 \mathbf{c},(R)-5 \mathbf{c},(S)-5 d$ and $(R)-5 d$ and their corresponding quaternized analogs $(S)-$ 6c, (R)-6c, (S)-6d and (R)-6d, respectively, would exhibit different pharmacological properties at the nAChRs. Characterization of $(S)-5 \mathbf{d}$ and $(R)-5 d$ revealed that the $\alpha 4 \beta 2$ activity resides in the $(R)$ enantiomer, (R)-5d displaying $\mathrm{K}_{\mathrm{i}}$ values of $2.5, \sim 100$ and $\sim 100 \mu \mathrm{M}$ at the $\alpha 4 \beta 2, \alpha 4 \beta 4$ and $\alpha 3 \beta 4$, respectively (Table 3). (S)-6d and (R)-6d displayed similar tendencies with $(R)-6 \mathbf{d}$ exhibiting $\mathrm{K}_{\mathrm{i}}$ values of 2.4, 25 and $\sim 25 \mu \mathrm{M}$ at the $\alpha 4 \beta 2, \alpha 4 \beta 4$ and $\alpha 3 \beta 4$ receptors, respectively. As observed in Table 3, compounds (S)-5c and (R)-5c displayed higher affinity for the $\alpha 4 \beta 2$ receptor than (S)-5d and (R)-5d [(S)- and (R)-crispine-A, respectively]. Moreover, $(R)$-5c exhibited $\sim 25$-fold higher binding affinity $\left(\mathrm{K}_{\mathrm{i}}\right.$ $=0.17 \mu \mathrm{M})$ than $(S)-5 \mathrm{c}$ at this subtype. The corresponding quaternary ammonium salts were also tested, and here the $\alpha 4 \beta 2$ activity was also found to reside in one enantiomer as (R)-6c displayed $K_{\mathrm{i}}$ values of 0.045, 2.7 and $11 \mu \mathrm{M}$ at the $\alpha 4 \beta 2, \alpha 4 \beta 4$ and $\alpha 3 \beta 4$, respectively. Notably, $(R)-6 \mathrm{c}$ exhibited $\sim 10$-fold higher binding affinities than DH $\beta E$ itself at all of the three tested nAChRs $(\alpha 4 \beta 2, \alpha 4 \beta 4$ and $\alpha 3 \beta 4)$ (Table 3, Figure 4B). These differences in the $\alpha 4 \beta 2$ activity between the $(S)$ - and $(R)$-enantiomers were mirrored in the functional properties as $(R)-5 \mathbf{c},(R)-5 \mathbf{d},(R)-6 \mathbf{c}$ and $(R)-6 \mathbf{d}$ displayed $\sim 23-,>6-,>450-$ and >14-fold lower $\mathrm{IC}_{50}$ values, respectively, than their respective $(S)$-enantiomers at the receptor in the FMP assay (Table 3). (R)-6c was the most potent $\alpha 4 \beta 2$ antagonist in the series, displaying an $\mathrm{IC}_{50}$ value of $0.22 \mu \mathrm{M}$ and $\sim 230$ fold selectivity for this receptor over the $\alpha 3 \beta 4$ subtype (Table 3, Figure 4B).

The tricyclic derivative (R)-6c displayed significantly higher binding affinity and somewhat higher antagonist potency at the $\alpha 4 \beta 2 \mathrm{nAChR}$ than $\mathrm{DH} \beta \mathrm{E}$. Since $(R)-6 \mathrm{c}$ also exhibited higher binding affinities at $\alpha 4 \beta 4$ and $\alpha 3 \beta 4 \mathrm{nAChRs}$ and also is a fairly potent $\alpha 7 \mathrm{nAChR}$ agonist, it cannot be claimed to be a more selective $\beta 2-n A C h R$ antagonist than DH $\beta E$ (Table 3, Figures 4B and 4C). However, considering its high antagonist potency at $\alpha 4 \beta 2$ and being a much more accessible scaffold for derivatization efforts than $\mathrm{DH} \beta \mathrm{E}$, we propose that this ligand could be an interesting lead structure for the future development of $\beta 2-n A C h R$ selective antagonists. Alternatively, some of the several potent and truly selective $\alpha 4 \beta 2$ antagonists identified in this study (for example, analogs 3e-f and 5c) could be applied in such efforts. 
Functional properties of the analogs at the $\alpha 7 n A C h R$. The functional properties of the ligands at the $\alpha 7$ nAChR were investigated at a HEK293 cell line stably co-expressing the receptor with the Ric-3 and NACHO proteins in the $\mathrm{Ca}^{2+} /$ Fluo-4 assay. ${ }^{47,48}$ Agonist-induced responses through the $\alpha 7$ nAChR in these cells could not be detected in the assay unless the assay buffer was supplemented with PNU120596 ( $3 \mu \mathrm{M}$ ), an $\alpha 7 \mathrm{nAChR}$ PAM that exerts its modulatory effects by dramatically slowing down the extremely fast desensitization of the receptor. ${ }^{49,50}$ Thus, the presence of PNU-120596 in the assay means that the functional properties of the ligands were determined at essentially non-desensitizing $\alpha 7$ receptors. Nevertheless, the functionalities as well as the rank orders of agonist and antagonist potencies exhibited by a selection of 8 reference agonists and 4 reference antagonists at the receptor in the assay were found to be in good agreement with the pharmacological properties reported for the ligands in the literature (see the Supporting Information for more details). Hence, while the presence of PNU-120596 in the assay certainly should be kept in mind and caution should be taken when it comes to the absolute values for potencies and efficacies displayed by the ligands in the assay, we propose that the basic functionalities exhibited by the ligands as well as the rank order of their potencies are likely to reflect their true pharmacological characteristics at the receptor.

In concordance with the SAR displayed by compounds 1-6 at the $\alpha 4 \beta 2$ nAChR, the

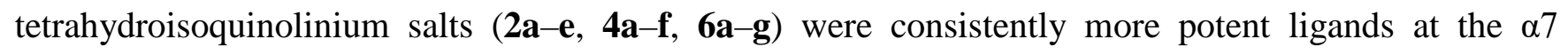
nAChR than their corresponding tetrahydroisoquinolines (1, 3a-f, $\mathbf{5} \mathbf{c}-\mathbf{g})$ (Tables $1-3)$. In fact, the differences in the activities exhibited by the respective analogs at the $\alpha 7$ receptor were even more pronounced than at the $\alpha 4 \beta 2 \mathrm{nAChR}$. With the exception of $5 \mathbf{a}-\mathbf{b}$ that displayed weak but significant $\alpha 7$ antagonism, all tetrahydroisoquinolines $(\mathbf{1}, \mathbf{3 a}-\mathbf{f}, \mathbf{5} \mathbf{c}-\mathbf{g})$ displayed negligible activity at the $\alpha 7 \mathrm{nAChR}$. In contrast, the tetrahydroisoquinolinium salts (2a-e, $4 \mathbf{a}-\mathbf{f}, \mathbf{6 a}-\mathbf{g}$ ) were not only more potent $\alpha 7$ ligands but displayed a wide range of receptor functionalities, ranging from being moderately potent antagonists $\left(2 \mathbf{e}, \mathrm{IC}_{50}=2.0 \mu \mathrm{M}\right.$ ) over fairly potent agonists (for example 4e and $6 \mathbf{e}$ with $\mathrm{EC}_{50}$ values of $0.99 \mu \mathrm{M}$ and $1.2 \mu \mathrm{M}$, respectively) to other apparently potent agonists that displayed notable biphasic concentration- 
response curves $(\mathbf{4 a}-\mathbf{b}, \mathbf{6 a}-\mathbf{b})$. The most potent agonists in the series displayed $\mathrm{EC}_{50}$ values comparable to those exhibited by $\mathrm{ACh},(S)$-nicotine and (-)-cytisine at the receptor, while not being nearly as potent as other reference nAChR agonists such as $( \pm)$-epibatidine and varenicline or as the $\alpha 7$-selective agonists TC-1698 and PNU-282987 (see the Supporting Information for more details).

As described above, quaternization of the tetrahydroisoquinoline scaffold yielded compounds with increased $\alpha 7 \mathrm{nAChR}$ activity. As an example of this, the inactivity of $\mathbf{1}$ at the receptor (both as agonist and antagonist) was contrasted by the pronounced agonist activity displayed by the corresponding tetrahydroisoquinolinium salt 2a (EC50 value of $9.0 \mu \mathrm{M})$. The introduction of an ethyl, propyl or allyl group on the nitrogen completely eliminated the $\alpha 7$ activity (2b-d), which could be a reflection of steric clashes between these bigger aliphatic substituents and some of the residues forming the orthosteric binding site. However, the benzyl-substituted analog $2 \mathbf{e}$ displayed potent antagonist activity at the receptor ( $\mathrm{IC}_{50}$ value of $2.0 \mu \mathrm{M}$ ). Thus, the aromatic substituent is either able to fit into the binding pocket or alternatively protrudes into a vestibule adjacent to the orthosteric site. Whichever way 2e accommodates binding to $\alpha 7$, it is clearly not able to trigger channel gating in the receptor, in contrast to the methyl analog 2a. Furthermore, judging from the negligible activity displayed by $\mathbf{2 e}$ at $\alpha 4 \beta 2$ and the other heteromeric nAChRs, this analog could be an interesting lead compound for future development of selective $\alpha 7 \mathrm{nAChR}$ antagonists. In this respect, it is interesting to note that ligands $\mathbf{4 c}$ and $\mathbf{4 e}$ (the 6,7-methylenedioxy and 7-hydroxy-6-methoxy analogs of 2a, respectively) are considerably more potent $\alpha 7$ agonists than 2a with $\mathrm{EC}_{50}$ values of 2.6 and $0.99 \mu \mathrm{M}$, respectively. Thus, introduction of a benzyl group on the nitrogen in this series could potentially yield more potent antagonists.

In 4a-f, the 6- and 7-substituents on the tetrahydroisoquinolinium scaffold were varied compared to the 6,7-dimethoxy analog 2a. As mentioned above, the 7-hydroxy-6-methoxy 4e and 6,7-methylenedioxy 4c analogs were both considerably more potent $\alpha 7$ agonists than 2a, whereas 6-methoxy $\mathbf{4 f}$ essentially was equipotent with $\mathbf{2 a}$ at the receptor (Table 1). Analogously to the inactivity of $\mathbf{4 d}$ at the heteromeric nAChRs, introduction of a dMBn group in the C1-position also almost completely eliminated its $\alpha 7$ 
activity. Interestingly, introduction of benzyloxy substituents in either the 6-position or the 7-position of the tetrahydroisoquinolinium scaffold resulted in derivatives 4a-b that while displaying agonist activities in the same concentration ranges as ligands $\mathbf{4} \mathbf{c}$ and $\mathbf{4 e}$ also displayed distinctly biphasic concentration-response curves. It is tempting to ascribe the decreased agonist responses observed at higher concentrations of these analogs to increased degrees of receptor desensitization, despite the presence of PNU-120596 in the assay and even though the other agonists in the series did not exhibit this characteristic. However, in view of the rather coarse measurement of $\alpha 7 \mathrm{nAChR}$ signaling provided by this assay, solid conclusions on the underlying basis for these signaling characteristics will have to await electrophysiology studies. Nevertheless, it is interesting to note that $\mathbf{6 a}-\mathbf{b}$, the tricyclic derivatives corresponding to $\mathbf{4 a - b}$, display very similar biphasic concentration-response curves and thus this signaling phenotype was exclusively observed for derivatives comprising a benzyloxy substituent.

The agonist properties displayed by the tricyclic analogs $\mathbf{6 a -}-\mathbf{g}$ were comparable to those exhibited by the bicyclic derivatives $\mathbf{4 a - f}$ with similar substituents on the catechol moiety (Tables 1-2). Thus, $\mathbf{6 c - g}$ displayed low-micromolar EC $_{50}$ values as $\alpha 7 \mathrm{nAChR}$ agonists and $\mathbf{6 a - b}$ displayed similar biphasic concentration-response curves at the receptors as the bicyclic analogs $\mathbf{4 a - b}$.

In vivo evaluation. Since the compounds $(R)-\mathbf{5 c}$ and $(R)-\mathbf{6 c}$ displayed the highest antagonist potencies at the $\alpha 4 \beta 2$ nAChR in vitro, and given the fact that a similar ligand has been found to possess antidepressant-like activity, ${ }^{25}$ these two analogs were selected for preliminary in vivo evaluations (Figure 5). (R)-5c and (R)-6c were tested in the mouse forced swim test, ${ }^{51}$ showing that both compounds significantly increased swimming activity. Ligand $(R)-5 c$ showed the most pronounced effect (ANCOVA: significant main effect of treatment $\left.\left(\mathrm{F}_{3,32}=5.98 ; \mathrm{p}<0.01\right)\right)$, showing a dose-dependent increase in swimming behavior. Pairwise comparisons revealed a near-significant effect of $1(\mathrm{p}=0.08)$ and $3 \mathrm{mg} / \mathrm{kg}(\mathrm{p}=0.06)$ and a significant effect of $10 \mathrm{mg} / \mathrm{kg}(\mathrm{p}<0.001)$. For compound $(R)-\mathbf{6 c}$, there was no significant main effect of treatment $\left(\mathrm{F}_{3,32}=1.87 ; \mathrm{p}=0.154\right)$, but pairwise comparisons revealed that swimming was significantly increased by $10 \mathrm{mg} / \mathrm{kg}(\mathrm{p}<0.05)$. Compound 1 , previously shown to exhibit 
antidepressant-like properties in the mFST, albeit at higher doses, is included in Fig. 5 for comparison (Crestey et al., 2013).

These findings are in line with several previous studies showing antidepressant-like effects in mice following antagonism of nAChRs, ${ }^{52,53}$ and the antidepressant-like effect of mecamylamine was revealed to depend on both $\beta 2$ - and $\alpha 7$ - subunit containing nAChRs. ${ }^{53}$ Female NMRI mice similar to those used in the present study have previously shown antidepressant-like responses to the non-selective nAChR antagonist mecamylamine as well as $\alpha 4 \beta 2$ - and $\alpha 7$-selective nAChR antagonists. ${ }^{54}$ Although the $\alpha 7$ nAChR agonist PNU-282987 by itself did not affect swimming in the mFST, it enhanced the effects mediated by the selective serotonin reuptake inhibitor citalopram and of the selective norepinephrine reuptake inhibitor reboxetine. ${ }^{51,54,55}$ Therefore, it is possible that $\alpha 7 \mathrm{nAChR}$ agonism counteracts the antidepressant-like effect of $\alpha 4 \beta 2 \mathrm{nAChR}$ antagonism, causing the combined $\alpha 4 \beta 2$ antagonism/ $\alpha 7$ agonism profile of $(R)-6 \mathrm{c}$ to be less efficacious than the more selective $\alpha 4 \beta 2 \mathrm{nAChR}$ antagonist $(R)-5 \mathrm{c}$. Another explanation could be that the fixed positive charge on (R)-6c inhibits transport across the blood-brain barrier.

\section{CONCLUSIONS}

We have investigated the effects of quaternizing several series of tetrahydroisoquinoline derivatives in the search of new nAChR ligands. We found that the $N$-methylation of $O$-methylcorypalline (1) was well tolerated whereas quaternization with larger substituents led to reduced activity at the $\alpha 4 \beta 2$ nAChR. Subsequent quaternization of similar ligands with methyl iodide provided compounds displaying increased binding affinities and antagonist potencies at the $\alpha 4 \beta 2 \mathrm{nAChR}$. The most potent compound (6c) was resolved and we found that the pharmacological activity at the $\alpha 4 \beta 2 \mathrm{nAChR}$ resides solely in the (R)-enantiomer. The in vitro data at the $\alpha 4 \beta 2 \mathrm{nAChR}$ were in good agreement with the results arising from the docking studies, providing an excellent starting point for the design and synthesis of new ligands. Preliminary in vivo evaluations indicated antidepressant-like effect of $(R)$-5c 
and $(R)-6 \mathbf{c}$ in the mouse forced swim test which were consistent with previous reports of antidepressant action of nAChR antagonists.

The 40 ligands investigated in this study revealed new compounds with interesting profiles at the nAChRs. We identified potent and selective $\alpha 4 \beta 2$ nAChR antagonists displaying negligible activities at the other major neuronal nAChRs and several dual $\alpha 4 \beta 2 / \alpha 7$ nAChR ligands displaying potent $\alpha 4 \beta 2$ antagonism and potent $\alpha 7$ agonism. With $\alpha 4 \beta 2$ being the only $\beta 2$-containing $n A C h R s$ included in this study, it remains to be clarified whether the compounds, analogously to DH $\beta E$, also possess activity at other $\beta 2$-containing subtypes. 


\section{EXPERIMENTAL SECTION}

Chemistry - Material and Methods. Reagents were obtained from commercial suppliers and used without further purifications. Syringes which were used to transfer anhydrous solvents or reagents were purged with nitrogen prior to use. Other solvents were analytical or HPLC grade and were used as received. Yields refer to isolated compounds estimated to be $>95 \%$ pure as determined by HPLC and LC-MS. Thin-layer chromatography (TLC) was carried out on silica gel $60 \mathrm{~F}_{254}$ plates from Merck (Germany). Visualization was accomplished under UV lamp (254 nm). Flash column chromatography was performed on chromatography grade, silica gel $60 \AA$ particle size 35-70 micron from Fisher Scientific using the solvent system as stated. Microwave-assisted synthesis was carried out in a Biotage Initiator apparatus operating in single mode; the microwave cavity producing controlled irradiation at 2.45 GHz (Biotage AB, Uppsala, Sweden). The reactions were run in sealed vessels. These experiments were performed by employing magnetic stirring and a fixed hold time using variable power to reach (during 1-2 $\mathrm{min}$ ) and then maintain the desired temperature in the vessel for the programmed time period. The temperature was monitored by an IR sensor focused on a point on the reactor vial glass. The

IR sensor was calibrated to internal solution reaction temperature by the manufacturer. ${ }^{1} \mathrm{H}$ and ${ }^{13} \mathrm{C}$ NMR spectra were recorded on Varian 300 (Mercury and Gemini instruments) or on Bruker (400 and 600 $\mathrm{MHz}$ ) instruments, using $\mathrm{CDCl}_{3}$ or DMSO- $d_{6}$ as deuterated solvents and with the residual solvent as the internal reference. For all NMR experiments the deuterated solvent signal was used as the internal lock. Coupling constants ( $J$ values) are given in Hertz $(\mathrm{Hz})$. Multiplicities of ${ }^{1} \mathrm{H}$ NMR signals are reported as follows: s, singlet; d, doublet; dd, doublet of doublets; dt, doublet of triplets; t, triplet; q, quartet; m, multiplet; br, broad signal. Melting points (mp) were determined using an MPA100 Optimelt melting point apparatus and are uncorrected. High-resolution mass spectra (HRMS) were obtained using a Bruker Daltonics MicroTOF instrument.

\section{Synthesis and Analytical Data of Representative Compounds.}

6,7-Methylenedioxy-2,2-dimethyl-1,2,3,4-tetrahydroisoquinolin-2-ium iodide (4c). To a solution of 6,7-methylenedioxy-2-methyl-1,2,3,4-tetrahydroisoquinoline 3c (191 mg, 1 mmol, 1 equiv) in dry 
acetone $(3 \mathrm{~mL})$ was added methyl iodide (623 $\mu \mathrm{L}, 10 \mathrm{mmol}, 10$ equiv) at room temperature. The mixture was stirred for $12 \mathrm{~h}$ in the dark and then filtered. The resulting solid was washed with dry acetone to lead to pure 4c as a white solid (297 mg, $96 \%$ ); dec $216{ }^{\circ} \mathrm{C}$; ${ }^{1} \mathrm{H}$ NMR (300 MHz, DMSO- $d_{6}$ ): $\delta 6.85$ (s, 1H), 6.75 (s, 1H), 6.00 (s, 2H), 4.45 (s, 2H), 3.57-3.68 (m, 2H), 3.12 (s, 6H), 2.98-3.08 (m, 2H); ${ }^{13} \mathrm{C}$ NMR (75 MHz, DMSO-d6): $\delta$ 147.9, 147.1, 123.5, 120.5, 109.1, 107.2, 102.0, 63.0, 59.0, 51.3 (2C), 24.2; HRMS (APPI): $\mathrm{M}^{+}$found 206.1176. $\mathrm{C}_{12} \mathrm{H}_{16} \mathrm{NO}_{2}$ requires 206.1182.

8,9-Methylenedioxy-1,2,3,5,6,10b-hexahydropyrrolo[2,1-a]isoquinoline (5c). ${ }^{25}$ To a MW vial were successively added compound 8a (1.51 g, $6.01 \mathrm{mmol}, 1$ equiv), acetonitrile (13.2 mL) and $\mathrm{POCl}_{3}(4.61$ g, 30.05 mmol, 5 equiv) at room temperature. The MW vial was sealed and heated under MW conditions for $15 \mathrm{~min}$ at $150{ }^{\circ} \mathrm{C}$. Volatiles were removed under reduced pressure and the resulting material was dissolved in an $\mathrm{AcOH}-\mathrm{MeOH}(1: 12,13 \mathrm{~mL})$ mixture prior to addition of $\mathrm{NaBH}_{4}(0.91 \mathrm{~g}$, 24.04 mmol, 4 equiv) portionwise at $0{ }^{\circ} \mathrm{C}$ with resulting gas evolution. Once the effervescence vanished, the resulting mixture was transferred into a new MW vial which was sealed and heated under MW conditions for $15 \mathrm{~min}$ at $90{ }^{\circ} \mathrm{C}$. The reaction mixture was quenched with water $(25 \mathrm{~mL})$ and volatiles were removed under reduced pressure. The aqueous layer was extracted with DCM (2 x 40 $\mathrm{mL}$ ) then the combined organic layers were successively washed with a saturated aqueous solution of sodium bicarbonate and brine, dried over $\mathrm{MgSO}_{4}$, filtered and concentrated under reduced pressure. The resulting crude material was purified by column chromatography on silica gel using EtOAc-MeOHTEA (40:10:1) as eluent to provide $5 \mathrm{c}$ as a pale yellow oil which slowly solidified (0.68 g, $52 \%) ;{ }^{1} \mathrm{H}$ NMR (600 MHz, $\left.\mathrm{CDCl}_{3}\right): \delta 6.58$ (s, 1H), 6.55 (s, 1H), 5.88 (s, 2H), 3.34 (br t, $\left.J=8.4,1 \mathrm{H}\right), 3.14-3.18$ (m, 1H), 3.06-3.10 (m, 1H), 2.97-3.04 (m, 1H), 2.72 (br dt, $J=16.3$ and $J=3.8,1 \mathrm{H}), 2.52$ (q, $J=8.7$, 1H), 2.25-2.32 (m, 1H), 1.88-1.97 (m, 1H), 1.81-1.86 (m, 1H), 1.65-1.73 (m, 1H).

\section{In Vivo Pharmacology - Methods and Data Analysis.}

Methods: Mice ( $\mathrm{n}=9-10)$ were individually placed in a beaker (16 $\mathrm{cm}$ in diameter) filled to a height of $20 \mathrm{~cm}$ of water maintained at $23.5-24.5^{\circ} \mathrm{C}$. Total swim distance during the 6 min test period was 
automatically recorded by a camera mounted above the cylinders and stored on a computer equipped with Ethovision (Noldus, The Netherlands). Twenty-four hours prior to drug testing a pre-test was performed to establish baseline swim distance for each mouse. Compounds $(R)-5 \mathbf{c}$ and $(R)-6 \mathbf{c}$ were dissolved in saline $(0.9 \% \mathrm{NaCl})$ and given subcutaneously 15 min prior to testing in an injection volume of $10 \mathrm{~mL} / \mathrm{kg}$. Data analysis: The first minute was omitted from the data before statistical analysis. This is because animals generally swim extensively for the first minute, irrespective of treatment; hence, any true treatment effect only becomes apparent after one minute. Swim distance was analyzed using a oneway analysis of covariance (ANCOVA) and followed by pairwise comparisons of the predicted means using the Planned Comparisons procedure. To ensure variance homogeneity and normality, data were log-transformed before statistical analysis. Differences were considered significant for p $<0.05$.

\section{AUTHOR INFORMATION}

\section{Corresponding author}

*J.L.K.: Phone: +45 3533 6487. E-mail: jesper.kristensen@sund.ku.dk

\section{ORCID}

François Crestey: 0000-0001-7206-6939

Jesper Langgaard Kristensen: 0000-0002-5613-1267

\section{Author contributions}

F.C. and J.L.K. conceived and designed the project. C.B.M. and F.C. performed the organic/analytical chemistry and analyzed all the synthesized compounds. A.A.J. performed and analyzed the data from the in vitro pharmacology experiments. J.T.A. performed and analyzed the data from the in vivo pharmacology experiments. C.B.M., C.S. and G.H.J.P. performed and analyzed the data from the docking study. The manuscript was written through contributions of all authors who gave approval to the final version of the manuscript. ${ }^{\S}$ A.A.J. and F.C. contributed equally to this work.

\section{Notes}

The authors declare no competing financial interest. 


\section{ACKNOWLEDGMENTS}

Generous financial support from the Danish Council for Independent Research - Medical Sciences, the Lundbeck Foundation, the Augustinus Foundation and the Novo Nordisk Foundation are gratefully acknowledged. The authors also thank Kasper Skytte Harpsøe, Karla Frydenvang, Camilla Koch and Birgitte Nielsen for experimental assistance and helpful discussions.

\section{ABBREVIATIONS USED}

HPLC: high-performance liquid chromatography; MW: microwave; DCM: dichloromethane; AcOH: acetic acid; MeOH: methanol; TEA: triethylamine; EtOAc: ethyl acetate; Bn: benzyl; dMBn: 3,4dimethoxybenzyl; ee: enantiomeric excess; DH $\beta E$ : dihydro- $\beta$-erythroidine; nAChR: nicotinic acetylcholine receptor; MLA: methyllycaconitine; HEK: human embryonic kidney; PAM: positive allosteric modulator; SAR: structure-activity relationship; FMP: FLIPR Membrane Potential Blue; S.E.M.: standard error of the mean.

\section{ASSOCIATED CONTENT}

Supporting Information. Complete biological evaluation data and full experimental details on the synthesis of the reported compounds, Molecular Formula Strings, chiral HPLC separation, optical rotation measurements and additional docking data are provided - including copies of ${ }^{1} \mathrm{H}$ and ${ }^{13} \mathrm{C}$ NMR spectra. This material is available free of charge via the Internet at http://pubs.acs.org.

\section{REFERENCES}

(1) Jensen, A. A.; Frølund, B.; Liljefors, T.; Krogsgaard-Larsen, P. Neuronal Nicotinic Acetylcholine Receptors: Structural Revelations, Target Identifications, and Therapeutic Inspirations. J. Med. Chem. 2005, 48, 4705-4745. 
(2) Arneric, S. P.; Holladay, M.; Williams, M. Neuronal Nicotinic Receptors: A Perspective on Two Decades of Drug Discovery Research. Bio. Pharmacol. 2007, 74, 1092-1101.

(3) Philip, N. S.; Carpenter, L. L.; Tyrka, A. R.; Price, L. H. Nicotinic Acetylcholine Receptors and Depression: A Review of the Preclinical and Clinical Literature. Psychopharmacology 2010, 212, $1-12$.

(4) Lemoine, D.; Jiang, R.; Taly, A.; Chataigneau, T.; Specht, A.; Grutter, T. Ligand-Gated Ion Channels: New Insights into Neurological Disorders and Ligand Recognition. Chem. Rev. 2012, 112, 6285-6318.

(5) Jensen, A. A.; Mikkelsen, I.; Frølund, B.; Bräuner-Osborne, H.; Falch, E.; Krogsgaard-Larsen, P. Carbamoylcholine Homologs: Novel and Potent Agonists at Neuronal Nicotinic Acetylcholine Receptors. Mol. Pharmacol. 2003, 64, 865-875.

(6) Gündisch, D. Nicotinic Acetylcholine Receptor Ligands as Potential Therapeutics. Expert Opin. Ther. Patents 2005, 15, 1221-1239.

(7) Gündisch, D.; Eibl, C. Nicotinic Acetylcholine Receptor Ligands, a Patent Review (2006-2011). Expert Opin. Ther. Patents 2011, 21, 1867-1896.

(8) Freedman, R. $\alpha$ 7-Nicotinic Acetylcholine Receptor Agonists for Cognitive Enhancement in Schizophrenia. Annu. Rev. Med. 2014, 65, 245-261.

(9) Grupe, M.; Grunnet, M.; Bastlund, J. F.; Jensen, A. A. Targeting $\alpha 4 \beta 2$ Nicotinic Acetylcholine Receptors in Central Nervous System Disorder: Perspectives on Positive Allosteric Modulation as a Therapeutic Approach. Basic Clin. Pharmacol. Toxicol. 2015, 116, 187-200, and references cited therein.

(10) Dwoskin, L. P.; Crooks, P. A. Competitive Neuronal Nicotinic Receptor Antagonists: A New Direction for Drug Discovery. J. Pharmacol. Exp. Ther. 2001, 298, 395-402. 
(11) Dwoskin, L. P.; Bardo, M. T. Targeting Nicotinic Receptor Antagonists as Novel Pharmacotherapies for Tobacco Dependence and Relapse. Neuropsychopharmacology 2009, 34, 244-246.

(12) Iturriaga-Vásquez, P.; Carbone, A.; García-Beltrán, O.; Livingstone, P. D.; Biggin, P. C.; Cassels, B. K.; Wonnacott, S.; Zapata-Torres, G.; Bermudez, I. Molecular Determinants for Competitive Inhibition for $\alpha 4 \beta 2$ Nicotinic Acetylcholine Receptors. Mol. Pharm. 2010, 78, 366375.

(13) Carroll, F. I.; Blough, B. E.; Mascarella, S. W.; Navarro, H. A.; Eaton, J. B.; Lukas, R. J.; Damaj, M. I. Synthesis and Biological Evaluation of Bupropion Analogues as Potential Pharmacotherapies for Smoking Cessation. J. Med. Chem. 2010, 53, 2204-2214.

(14) Ambrus, J. I.; Halliday, J. I.; Kanizaj, N.; Absalom, N.; Harpsøe, K.; Balle, T.; Chebib, M.; McLeod, M. D. Covalent Attachment of Antagonists to the $\alpha 7$ Nicotinic Acetylcholine Receptor: Synthesis and Reactivity of Substituted Maleimides. Chem. Commun. 2012, 48, 6699-6701.

(15) Faundez-Parraquez, M.; Farias-Rabelo, N.; Gonzalez-Gutierrez, J. P.; Etcheverry-Berrios, A.; Alzate-Morales, J.; Adasme-Carreño, F.; Varas, R.; Bermudez, I.; Iturriaga-Vásquez, P. Neonicotinic Analogues: Selective Antagonists for $\alpha 4 \beta 2$ Nicotinic Acetylcholine Receptors. Bioorg. Med. Chem. 2013, 21, 2687-2694.

(16) Jepsen, T. H.; Jensen, A. A.; Lund, M. H.; Glibstrup, E.; Kristensen, J. L. Synthesis and Pharmacological Evaluation of DH $\beta$ E Analogues as Neuronal Nicotinic Acetylcholine Receptor Antagonists. ACS Med. Chem. Lett. 2014, 5, 766-770.

(17) Crooks, P. A.; Bardo, M. T.; Dwoskin, L. P. Nicotinic Receptor Antagonists as Treatment for Nicotine Abuse. Adv. Pharmacol. 2014, 69, 513-551. 
(18) Petersen, I. N.; Crestey, F.; Jensen, A. A.; Indurthi, D. C.; Pedersen, H.; Andreasen, J. T.; Balle, T.; Kristensen, J. L. Tying up Nicotine: New Competitive Antagonist of the Neuronal Nicotinic Acetylcholine Receptors. ACS Med. Chem. Lett. 2015, 6, 472-475.

(19) Jaikhan, P.; Boonyarat, C.; Arunrungvichian, K.; Taylor, P.; Vajragupta, O. Design and Synthesis of Nicotinic Acetylcholine Receptor Antagonists and Their Effect on Cognitive Impairment. Chem. Biol. Drug Des. 2016, 87, 39-56.

(20) Ondachi, P. W.; Castro, A. H.; Sherman, B.; Luetje, C. W.; Damaj, M. I.; Mascarella, S. W.; Navarro, H. A.; Carroll, F. I. Synthesis, Nicotinic Acetylcholine Receptor Binding, and in Vitro and in Vivo Pharmacological Properties of 2'-Fluoro-(substituted thiophenyl)-deschloroepibatidine Analogues. ACS Chem. Neurosci. 2017, 8, 115-127, and references cited therein.

(21) Reimann, E. Synthesis Pathways to Erythrina Alkaloids and Erythrina Type Compounds. Progress in the Chemistry of Organic Natural Products 2007, 88, 1-62.

(22) Shahsavar, A.; Kastrup, J. S.; Nielsen, E. Ø.; Kristensen, J. L.; Gajhede, M.; Balle, T. Crystal Structure of Lymnaea stagnalis AChBP Complexed with the Potent nAChR Antagonist DH $\beta E$ Suggests a Unique Mode of Antagonism. PLoS One 2012, 7, e40757.

(23) Theuns, H. G.; Vlietstra, E. J.; Salemink, C. A. Corypalline and O-Methylcorypalline, Two Alkaloids from Papaver bracteatum. Phytochemistry 1983, 22, 247-250.

(24) Menachery, M. D.; Lavanier, G. L.; Wetherly, M. L.; Guinaudeau, H.; Shamma, M. Simple Isoquinoline Alkaloids. J. Nat. Prod. 1986, 49, 745-778.

(25) Crestey, F.; Jensen, A. A.; Borch, M.; Andreasen, J. T.; Andersen, J.; Balle, T.; Kristensen, J. L. Design, Synthesis and Biological Evaluation of Erythrina Alkaloid Analogues as Neuronal Nicotinic Acetylcholine Receptor Antagonists. J. Med. Chem. 2013, 56, 9673-9682. 
(26) Jepsen, T. H.; Glibstrup, E.; Crestey, F.; Jensen, A. A.; Kristensen, J. L. Strategic Approach to [6,6]-Bicyclic Lactones: Application Towards the CD Fragment of DH $\beta E$. Beilstein J. Org. Chem. 2017, 13, 988-994.

(27) Søkilde, B.; Mikkelsen, I.; Stensbøl, T. B.; Andersen, B.; Ebdrup, S.; Krosgaard-Larsen, P.; Falch, E. Analogues of Carbacholine: Synthesis and Relationship Between Structure and Affinity for Muscarinic and Nicotinic Acetylcholine Receptors. Arch. Pharm. 1996, 329, 95-104.

(28) Papke, R. L.; Bencherif, M.; Lippiello, P. An Evaluation of Neuronal Nicotinic Acetylcholine Receptor Activation by Quaternary Nitrogen Compounds Indicates that Choline is Selective for the a7 Subtype. Neurosci. Lett. 1996, 213, 201-204.

(29) Coates, K. M.; Flood, P. Ketamine and its Preservative, Benzethonium Chloride, Both Inhibit Human Recombinant $\alpha 7$ and $\alpha 4 \beta 2$ Neuronal Nicotinic Acetylcholine Receptors in Xenopus Oocytes. Br. J. Pharmacol. 2001, 134, 871-879.

(30) Iturriaga-Vásquez, P.; Pérez, E. G.; Slater, E. Y.; Bermúdez, I.; Cassels, B. K. Aporphine Metho Salts as Neuronal Nicotinic Acetylcholine Receptor Blockers. Bioorg. Med. Chem. 2007, 15, 3368-3372.

(31) For example, pancuronium bromide (trademarked as Pavulon) and atracurium besilate (trademarked as Tracrium) are still used for euthanasia and anaesthesia, respectively. Moreover, vecuronium bromide (trademarked as Norcuron), doxacurium chloride and mivacurium chloride are used as skeletal muscle relaxation during surgery. Hexamethonium chloride, used to treat chronic hypertension, inhibits the ganglionic nicotinic receptors.

(32) Dwoskin, L. P.; Leibee, L. L.; Jewell, A. L.; Fang, Z.-X.; Crooks, P. A. Inhibition of $\left[{ }^{3} \mathrm{H}\right]$ Dopamine Uptake into Rat Striatal Slices by Quaternary N-Methylated Nicotine Metabolites. Life Sci. 1992, 50, 233-237. 
(33) Crooks, P. A.; Ravard, A.; Wilkins, L. H.; Teng, L.-H.; Buxton, S. T.; Dwoskin, L. P. Inhibition of Nicotine-Evoked [ $\left.{ }^{3} \mathrm{H}\right]$ Dopamine Release by Pyridino N-Substituted Nicotine Analogues: A New Class of Nicotinic Antagonists. Drug Dev. Res. 1995, 36, 91-102.

(34) Ayers, J. T.; Dwoskin, L. P.; Deaciuc, A. G.; Grinevich, V. P.; Zhu, J.; Crooks, P. A. BisAzaaromatic Quaternary Ammonium Analogues: Ligands for $\alpha 4 \beta 2 *$ and $\alpha 7 *$ Subtypes of Neuronal Nicotinic Receptors. Bioorg. Med. Chem. Lett. 2002, 12, 3067-3071.

(35) Wilkins, Jr., L. H.; Grinevich, V. P.; Ayers, J. T.; Crooks, P. A.; Dwoskin, L. P. N-nAlkylnicotinium Analogs, a Novel Class of Nicotinic Receptor Antagonists: Interaction with $\alpha 4 \beta 2 *$ and $\alpha 7 *$ Neuronal Nicotinic Receptors. J. Pharmacol. Exp. Ther. 2003, 304, 400-410.

(36) Grinevich, V. P.; Crooks, P. A.; Sumithran, S. P.; Haubner, A. J.; Ayers, J. T.; Dwoskin, L. P. Nn-Alkylpyridinium Analogs, a Novel Class of Nicotinic Receptor Antagonists: Selective Inhibition of Nicotine Evoked [ $\left.{ }^{3} \mathrm{H}\right]$ Dopamine Overflow from Superfused Rat Striatal Slices. J. Pharmacol. Exp. Ther. 2003, 306, 1011-1020.

(37) Imming, P.; Klaperski, P.; Stubbs, M. T.; Seitz, G.; Gündisch, D. Syntheses and Evaluation of Halogenated Cytisine Derivatives and of Bioisosteric Thiocytisine as Potent and Selective nAChR Ligands. Eur. J. Med. Chem. 2001, 36, 375-388.

(38) Lukas, R. J. Pharmacological Distinctions between Functional Nicotinic Acetylcholine Receptors on the PC12 Rat Pheochromocytoma and the TE671 Human Medulloblastoma. J. Pharmacol. Exp. Ther. 1989, 251, 175-182.

(39) Rowles, I.; Malone, K. J.; Etchells, L. L.; Willies, S. C.; Turner, N. J. Directed Evolution of the Enzyme Monoamine Oxidase (MAO-N): Highly Efficient Chemo-enzymatic Deracemisation of the Alkaloid ( \pm )-Crispine A. ChemCatChem 2012, 4, 1259-1261. 
(40) Performing the reduction with $\mathrm{NaBH}_{4}$ (4 equiv) at room temperature in a mixture $\mathrm{MeOH}-\mathrm{AcOH}$ (12:1) overnight provided tetrahydroisoquinoline derivatives $\mathbf{5} \mathbf{c}$ and $\mathbf{5 d}$ within the same range of yields (or even higher) than when the reduction was performed under MW conditions

(41) The ee of (S)-5d after chiral HPLC separation was $95.9 \%$ while the ee of $(R)-\mathbf{5 d}$ was $99.3 \%$. See the Supporting Information for more details regarding the chiral HPLC separation as well as the optical rotation measurements in order to confirm the absolute configuration of the two enantiomers.

(42) The absolute configuration of the two enantiomers $(S)-5 c$ and $(R)-5 c$ was correctly assigned throughout the whole article although at the time of the study the absolute configuration was not formally yet established. The ee of (S)-5c after chiral HPLC separation was $97.0 \%$ while the ee of (R)-5c was 99.1\%. See the Supporting Information for more details.

(43) Friesner, R. A.; Murphy, R. B.; Repasky, M. P.; Frye, L. L.; Greenwood, J. R.; Halgren, T. A.; Sanschagrin, P. C.; Mainz, D. T. Extra Precision Glide: Docking and Scoring Incorporating a Model of Hydrophobic Enclosure for Protein-Ligand Complexes. J. Med. Chem. 2006, 49, 61776196.

(44) Morales-Perez, C. L.; Noviello, C. M.; Hibbs, R. E. X-ray Structure of the Human $\alpha 4 \beta 2$ Nicotinic Receptors. Nature 2016, 538, 411-415.

(45) Amiri, S.; Sansom, M. S. P.; Biggin, P. C. Molecular Dynamics Studies of AChBP with Nicotine and Carbamylcholine: the Role of Water in the Binding Pocket. Protein Eng., Des. Sel. 2007, 20, 353-359.

(46) Beers, W. H.; Reich, E. Structure and Activity of Acetylcholine. Nature 1970, 228, 917-922. 
(47) Williams, M. E.; Burton, B.; Urrutia, A.; Shcherbatko, A.; Chavez-Noriega, L. E.; Cohen, C. J.; Aiyar, J. Ric-3 Promotes Functional Expression of the Nicotinic Acetylcholine Receptor $\alpha 7$ Subunit in Mammalian Cells. J Biol Chem 2005, 280, 1257-1263.

(48) Gu, S.; Matta, J. A.; Lord, B.; Harrington, A. W.; Sutton, S. W.; Davini, W. B.; Bredt, D. S. Brain alpha7 Nicotinic Acetylcholine Receptor Assembly Requires NACHO. Neuron 2016, 89, 948-955.

(49) Hurst, R. S.; Hajós, M.; Raggenbass, M.; Wall, T. M.; Hidgon, N. R.; Lawson, J. A.; RutherfordRoot, K. L.; Berkenpas, M. B.; Hoffmann, W. E.; Piotrowski, D. W.; Groppi, V. E.; Allaman, G.; Ogier, R.; Bertrand, S.; Bertrand, D.; Arneric, S. P. A Novel Positive Allosteric Modulator of the a7 Neuronal Nicotinic Acetylcholine Receptor: In Vitro and In Vivo Characterization. J Neurosci 2005, 25, 4396-4405.

(50) Grønlien, J. H.; Håkerud, M.; Ween, H.; Thorin-Hagene, K.; Briggs, C. A.; Gopalakrishnan, M.; Malysz, J. Distinct Profiles of $\alpha 7$ nAChR Positive Allosteric Modulation Revealed by Structurally Diverse Chemotypes. Mol Pharmacol 2007, 72, 715-724.

(51) In this behavorial test, a mouse which has received the tested compound is place in an inescapable tank which is filled with water; the distance swum by the animal is measured. An increase in the swimming distance is interpreted as an antidepressant-like effect of the tested compound. For more details, see: Slattery, D. A.; Cryan, J. F. Using the Rat Forced Swim Test to Assess Antidepressant-like Activity in Rodents. Nature Protoc. 2012, 7, 1009-1014.

(52) Caldarone, B. J.; Harrist, A.; Cleary, M. A.; Beech, R. D.; King, S. L.; Picciotto, M. R. HighAffinity Nicotinic Acetylcholine Receptors Are Required for Antidepressant Effects of Amitriptyline on Behavior and Hippocampal Cell Proliferation. Biol. Psychiatry 2004, 56, 657664. 
(53) Rabenstein, R. L.; Caldarone, B. J.; Picciotto, M. R. The Nicotinic Antagonist Mecamylamine has Antidepressant-like Effects in Wild-Type but not $\beta 2$ - or $\alpha 7-N i c o t i n i c$ Acetylcholine Receptor Subunit Knockout Mice. Psychopharmacology (Berl). 2006, 189, 395-401.

(54) Andreasen, J. T.; Olsen, G. M.; Wiborg, O.; Redrobe, J. P. Antidepressant-like Effects of Nicotinic Acetylcholine Receptor Antagonists, but not Agonists, in the Mouse Forced Swim and Mouse Tail Suspension Tests. J Psychopharmacol. 2009, 23, 797-804.

(55) Andreasen, J. T.; Nielsen, E. Ø.; Christensen, J. K.; Olsen, G. M.; Peters, D.; Mirza, N. R.; Redrobe, J. P. Subtype-Selective Nicotinic Acetylcholine Receptor Agonists Enhance the Responsiveness to Citalopram and Reboxetine in the Mouse Forced Swim Test. $J$ Psychopharmacol. 2011, 25, 1347-1356. 


\section{FIGURES, SCHEMES AND TABLES TITLES}

Scheme 1. Synthesis of tetrahydroisoquinolinium derivatives $2 \mathbf{a}-\mathbf{e}, \mathbf{4 a}-\mathbf{f}$ and $\mathbf{6 a}-\mathbf{g}$. Reagents and conditions: (i) RX (10 equiv), acetone, rt or $35^{\circ} \mathrm{C}, 12$ h, 67-96\% for $\mathbf{2 a - e , ~ 6 5 - 9 6 \% ~ f o r ~} \mathbf{4 a - f , ~ 6 3 - 8 1 \% ~}$ for 6a-g. dMBn = 3,4-dimethoxybenzyl; Bn = benzyl.

Scheme 2. Synthesis of racemic derivatives $\mathbf{5 c}$ and $\mathbf{5 d}$ and tetrahydroisoquinolinium derivatives $(S)-\mathbf{6 c}$, (R)-6c, (S)-6d and (R)-6d. Reagents and conditions: (i) $\gamma$-butyrolactone (1.1 equiv), MW, $150{ }^{\circ} \mathrm{C}, 15$ min, $76 \%$ for $\mathbf{8 a}$, $70 \%$ for $\mathbf{8 b}$; (ii) a) $\mathrm{POCl}_{3}$ (5 equiv), $\mathrm{CH}_{3} \mathrm{CN}, \mathrm{MW}, 150{ }^{\circ} \mathrm{C}, 15 \mathrm{~min}$; b) $\mathrm{NaBH}_{4}(4$ equiv), $\mathrm{MeOH}-\mathrm{AcOH}$ (12:1), MW, $90{ }^{\circ} \mathrm{C}, 15$ min, 52\% for 5c, 30\% for 5d (within 2 steps); (iii) $\mathrm{CH}_{3} \mathrm{I}$ (15 equiv), acetone, rt, 2 h, 60\% for (S)-6c, 54\% for $(R)-6 \mathbf{c}, 42 \%$ for $(S)-6 d, 44 \%$ for $(R)-6 d$.

Table 1. Pharmacological properties of bicyclic compounds 1, 2, 3 and $\mathbf{4}$ at nAChRs.

Table 2. Pharmacological properties of tricyclic compounds 5 and $\mathbf{6}$ at nAChRs.

Table 3. Pharmacological properties of enantiopure tricyclic compounds 5 and $\mathbf{6}$ at nAChRs.

Figure 1. (A) Structures of $\mathrm{DH} \beta \mathrm{E},{ }^{26}$ erysodine, ${ }^{12}$ erysotrine ${ }^{12}$ and $O$-methylcorypalline (1). ${ }^{25}$ In parentheses are the $K_{i}$ values of the compounds at $\alpha 4 \beta 2$ nAChR subtype determined in a $\left[{ }^{3} \mathrm{H}\right]$ epibatidine (for $\mathrm{DH} \beta \mathrm{E}$ and 1) or $\left[{ }^{3} \mathrm{H}\right]$ cytisine (for erysotrine and erysodine) binding assay. (B) Retrosynthetic strategy towards tetrahydrosioquinolinium salts 2, 4 and $\mathbf{6}$ from derivatives 1, 3 and 5, respectively.

Figure 2. GlideXP docking of ligands 2a (green), 2b (orange) and 2c (red) explaining the order of affinity of the three ligands as a consequence of the limited space in the binding pocket. Docking experiments are based on the X-ray structure of the human $\alpha 4 \beta 2$ nicotinic receptors (PDB ID: $5 \mathrm{KXI}){ }^{44}$

Figure 3. GlideXP docking of (R)-6c (green) and (S)-6c (purple) seen from two different perspectives: (A) Here the interactions with three residues in the binding pocket are higligted. Hydrogen-bonds are shown in yellow dashed line while $\pi$-cation interactions are shown in green dashed lines. (B) Here the interactions with the water molecule and the size of the binding pocket are highligted. Hydrogen-bonds 
are shown in yellow dashed line while $\pi$-cation interactions are shown in green dashed lines. Docking experiments are based on the X-ray structure of the human $\alpha 4 \beta 2$ nicotinic receptors (PDB ID: $5 \mathrm{KXI}){ }^{44}$

Figure 4. In vitro pharmacological properties of tetrahydroisoquinolines and tetrahydroisoquinolinium salts at the nAChRs. (A) Pharmacological properties of the tetrahydroisoquinolines and tetrahydroisoquinolinium derivatives at the $\alpha 4 \beta 2 \mathrm{nAChR}$ in the $\left[{ }^{3} \mathrm{H}\right]$ epibatidine binding and FMP assays. Left and middle: Comparison between the binding affinities ( $\mathrm{pK}_{\mathrm{i}} \pm$ S.E.M., left) and antagonist potencies (pIC50 \pm S.E.M., middle) displayed by the tetrahydroisoquinolines 1, 3a-f, 5a-g, $(R)-5 \mathbf{c},(S)-$ 5c, $(R)-5 \mathbf{d}$ and $(S)-5 \mathbf{d}$ and the corresponding tetrahydroisoquinolinium salts $\mathbf{2 a}, \mathbf{4 a}-\mathbf{f}, \mathbf{6 a}-\mathbf{g},(R)-\mathbf{6 c},(S)-$ 6c, $(R)-6 \mathbf{d}$ and $(S)-6 d$ at the $\alpha 4 \beta 2$ nAChR. Right: Correlation between the binding affinities $\left(\mathrm{pK}_{\mathrm{i}} \pm\right.$ S.E.M.) and antagonist potencies (pIC $50 \pm$ S.E.M.) displayed by all active tetrahydroisoquinolines and tetrahydroisoquinolinium salts the $\alpha 4 \beta 2$ nAChR. (B) Binding properties of DH $\beta E,(R)-5 \mathrm{c}$ and $(R)-6 \mathrm{c}$ at nAChRs. Concentration-inhibition curves for DH $\beta E$, $(R)-5 c$ and $(R)-6 c$ at $\alpha 4 \beta 2, \alpha 3 \beta 4$ and $\alpha 4 \beta 4$ in the $\left[{ }^{3} \mathrm{H}\right]$ epibatidine binding assay. (C) Functional properties of $\mathrm{DH} \beta \mathrm{E},(R)-5 \mathrm{c}$ and $(R)-\mathbf{6 c}$ at nAChRs. Left: Concentration-inhibition curves for DH $\beta E,(R)-5 c$ and $(R)-6 c$ at $\alpha 4 \beta 2$ and $\alpha 3 \beta 4$ in the FMP assay and for $\mathrm{DH} \beta \mathrm{E}$ at $\alpha 7$ in the $\mathrm{Ca}^{2+} /$ Fluo-4 assay. Right: Concentration-response curves for $\mathrm{ACh},(R)-5 \mathrm{c}$ and (R)-6c at $\alpha 7$ in the $\mathrm{Ca}^{2+} /$ Fluo-4 assay (obtained in the presence of $3 \mu \mathrm{M}$ PNU-120596). Figures B and C depict data from single representative experiment performed as described in the Supporting Information and error bars are omitted for clarity.

Figure 5. Effects of $(R)-5 c(A)$ and $(R)-6 c(B)$ in the mouse forced swim test. The effect of the previously published ${ }^{25}$ compound 1 is included for comparison (C). ${ }^{*} \mathrm{p}<0.05$; ${ }^{* * *} \mathrm{p}<0.001(\mathrm{n}=9-10)$. 
Table $1^{a}$

\begin{tabular}{|c|c|c|c|c|c|c|c|}
\hline & \multicolumn{3}{|c|}{ Binding $\mathrm{K}_{\mathrm{i}}(\mu \mathrm{M})$} & \multicolumn{4}{|c|}{ Functional $(\mu \mathrm{M})$} \\
\hline Compound & $\alpha 4 \beta 2$ & $\alpha 4 \beta 4$ & $\alpha 3 \beta 4$ & $\alpha 4 \beta 2\left(\mathrm{IC}_{50}\right)$ & $\alpha 3 \beta 4\left(\mathrm{IC}_{50}\right)$ & $\alpha 7\left(\mathrm{IC}_{50}\right)$ & $\alpha 7\left(\mathrm{EC}_{50}\right)$ \\
\hline $\mathrm{DH} \beta \mathrm{E}$ & 0.65 & $\sim 25$ & $\sim 100$ & 0.60 & $\sim 100$ & $\sim 100$ & - \\
\hline 1 & 0.87 & $\sim 300$ & $\sim 300$ & 12 & $\sim 100$ & $>100$ & $>100$ \\
\hline $2 \mathbf{a}$ & 0.63 & $\sim 50$ & $\sim 100$ & 11 & $>300$ & - & 9.0 \\
\hline $2 \mathbf{b}$ & 9.7 & $>300$ & $>300$ & 11 & $>300$ & - & weak agonist $^{b}$ \\
\hline $2 c$ & 14 & $\sim 300$ & $\sim 300$ & $\sim 30$ & $>300$ & $>100$ & $>100$ \\
\hline 2d & $\sim 30$ & $\sim 300$ & $>300$ & $\sim 30$ & $>300$ & $>100$ & $>100$ \\
\hline $2 \mathbf{e}$ & $\sim 30$ & $>300$ & $\sim 300$ & $\sim 30$ & $>300$ & 2.0 & - \\
\hline 3a & 2.9 & $\sim 300$ & $\sim 300$ & 24 & $\sim 100$ & $\sim 30$ & - \\
\hline $3 \mathbf{b}$ & 15 & $\sim 300$ & $\sim 300$ & 23 & $>300$ & $\sim 30$ & - \\
\hline $3 c$ & 17 & $\sim 50$ & $\sim 300$ & 2.6 & $\sim 300$ & $>100$ & $>100$ \\
\hline 3d & $\sim 100$ & $>100$ & $>100$ & $>100$ & $>100$ & $>100$ & $>100$ \\
\hline $3 \mathbf{e}$ & 1.7 & $\sim 100$ & $\sim 100$ & 4.4 & $\sim 100$ & $>100$ & $>100$ \\
\hline $3 f$ & 2.6 & $\sim 25$ & $\sim 100$ & 6.2 & $>100$ & $>100$ & $>100$ \\
\hline $4 \mathbf{a}$ & 0.47 & $\sim 50$ & $\sim 30$ & 7.2 & $>300$ & - & agonist (biphasic) $^{d}$ \\
\hline $4 b$ & 4.5 & 17 & $\sim 30$ & $\sim 30$ & $>300$ & - & agonist (biphasic) ${ }^{d}$ \\
\hline
\end{tabular}




\begin{tabular}{l|ccc|cccc} 
4c & 0.38 & $\sim 30$ & $\sim 50$ & 12 & $>300$ & - & 2.6 \\
$\mathbf{4 d}$ & $>100$ & $>100$ & $>100$ & $>100$ & $>100$ & - & weak agonist $^{c}$ \\
$\mathbf{4 e}$ & 0.40 & 8.9 & $\sim 25$ & 1.2 & $>100$ & - & 0.99 \\
$\mathbf{4 f}$ & 0.68 & 1.5 & 9.3 & 1.4 & $>100$ & - & 4.4
\end{tabular}

${ }^{a}$ The binding properties of the compounds were determined with membranes from the stable r $\alpha 3 \beta 4-$, r $\alpha 4 \beta 4$ - and r $\alpha 4 \beta 2$ HEK293 cell lines in a $\left[{ }^{3} \mathrm{H}\right]$ epibatidine binding assay, while the functional properties of the compounds were determined

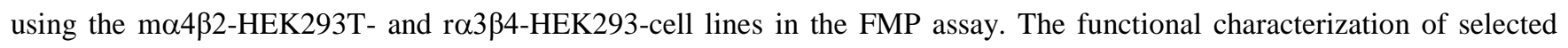
ligands at the human $\alpha 7 \mathrm{nAChR}$ was performed at the stable h $\alpha 7^{\text {Ric-3/NACHO}}-\mathrm{HEK} 293$ cell line in the Ca ${ }^{2+} /$ Fluo-4 assay in the presence of $3 \mu \mathrm{M}$ PNU-120596. The data were the means of 3-5 individual experiments performed in duplicate. The complete data set for this table (i.e., $\mathrm{K}_{\mathrm{i}}\left[\mathrm{pK} \mathrm{i}_{\mathrm{i}} \pm\right.$ S.E.M.] values from the binding experiments, $\mathrm{IC}_{50}$ [pIC $\mathrm{p}_{50} \pm$ S.E.M.], EC 50 [pEC $50 \pm$ S.E.M.] and $\mathrm{R}_{\max } \pm$ S.E.M. values from the functional experiments are given in the Supporting information. ${ }^{b, c}$ Agonist-concentration response curves not complete within the tested concentration range. Significant agonist responses observed at concentrations of $30 \mu \mathrm{M}^{b}$ or $10 \mu \mathrm{M}^{c} .{ }^{d}$ Agonist-concentration response curves were biphasic. The compounds elicited significant and concentration-dependent agonist responses at lower concentrations, whereas higher concentrations elicited smaller responses. Significant agonist responses that increased with increasing concentrations were observed for 1 and $3 \mu \mathrm{M}$ (compound $\mathbf{4 a}$ ) and for 0.3, 1 and $3 \mu \mathrm{M}$ (compound $\mathbf{4 b}$ ). At $10 \mu \mathrm{M}$ and higher concentrations, the agonist-induced responses decreased substantially. 
Table $2^{a}$

\begin{tabular}{|c|c|c|c|c|c|c|c|}
\hline & \multicolumn{3}{|c|}{ Binding $\mathrm{K}_{\mathrm{i}}(\mu \mathrm{M})$} & \multicolumn{4}{|c|}{ Functional $(\mu \mathrm{M})$} \\
\hline Compound & $\alpha 4 \beta 2$ & $\alpha 4 \beta 4$ & $\alpha 3 \beta 4$ & $\alpha 4 \beta 2\left(\mathrm{IC}_{50}\right)$ & $\alpha 3 \beta 4\left(\mathrm{IC}_{50}\right)$ & $\alpha 7\left(\mathrm{IC}_{50}\right)$ & $\alpha 7\left(\mathrm{EC}_{50}\right)$ \\
\hline $\mathrm{DH} \beta \mathrm{E}$ & 0.65 & $\sim 25$ & $\sim 100$ & 0.60 & $\sim 100$ & $\sim 100$ & - \\
\hline $5 a$ & 6.3 & $\sim 300$ & $\sim 100$ & $\sim 30$ & $\sim 100$ & 5.7 & - \\
\hline $5 \mathbf{b}$ & $\sim 50$ & $\sim 300$ & $\sim 300$ & $\sim 50$ & $>100$ & 11 & - \\
\hline $5 c$ & 0.50 & 9.3 & $>100$ & 2.3 & $\sim 100$ & - & weak agonist $^{b}$ \\
\hline $5 d$ & 4.6 & $\sim 100$ & $\sim 100$ & $\sim 30$ & $\sim 100$ & $>100$ & $>100$ \\
\hline $5 e$ & 1.4 & 3.3 & $\sim 100$ & 9.1 & $>100$ & - & weak agonist $^{b}$ \\
\hline $5 f$ & $\sim 25$ & $\sim 100$ & $>100$ & $\sim 100$ & $>100$ & $>100$ & $>100$ \\
\hline $5 g$ & 8.5 & $\sim 100$ & $\sim 100$ & 15 & $>100$ & $\sim 100$ & $>100$ \\
\hline $6 \mathbf{6 a}$ & 2.1 & $\sim 300$ & $\sim 300$ & 3.1 & $\sim 300$ & - & agonist (biphasic) ${ }^{c}$ \\
\hline $6 b$ & 11 & $\sim 300$ & $\sim 300$ & 5.7 & $\sim 300$ & - & agonist (biphasic) ${ }^{c}$ \\
\hline 6c & 0.14 & $\sim 50$ & $\sim 30$ & 0.52 & $\sim 30$ & - & 2.6 \\
\hline 6d & 2.4 & $\sim 30$ & $\sim 50$ & $\sim 30$ & $\sim 100$ & - & 7.5 \\
\hline $6 e$ & 0.23 & 0.92 & 9.3 & 1.8 & $\sim 50$ & - & 1.2 \\
\hline $6 f$ & 3.6 & 12 & $\sim 25$ & $\sim 30$ & $\sim 100$ & - & 5.2 \\
\hline $6 g$ & 17 & $\sim 25$ & $\sim 50$ & $\sim 50$ & $>100$ & - & 2.2 \\
\hline
\end{tabular}


${ }^{a}$ The binding properties of the compounds were determined with membranes from the stable r $\alpha 3 \beta 4-$, r $\alpha 4 \beta 4-$ and r $\alpha 4 \beta 2-$ HEK293 cell lines in a $\left[{ }^{3} \mathrm{H}\right]$ epibatidine binding assay while the functional properties of the compounds were determined

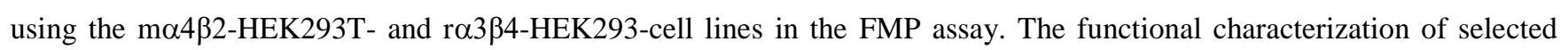
ligands at the human $\alpha 7 \mathrm{nAChR}$ was performed at the stable $h \alpha 7^{\mathrm{Ric}-3 / \mathrm{NACHO}}-\mathrm{HEK} 293$ cell line in the Ca ${ }^{2+} / \mathrm{Fluo}^{-4}$ assay in the presence of $3 \mu \mathrm{M}$ PNU-120596. The data were the means of 3-5 individual experiments performed in duplicate. The complete data set for this table (i.e., $\mathrm{K}_{\mathrm{i}}\left[\mathrm{pK} \mathrm{K}_{\mathrm{i}} \pm\right.$ S.E.M.] values from the binding experiments, $\mathrm{IC}_{50}$ [pIC $_{50} \pm$ S.E.M.], EC 50 [pEC50 \pm S.E.M.] and $\mathrm{R}_{\max } \pm$ S.E.M. values from the functional experiments are given in the Supporting information. ${ }^{b}$ Agonist-concentration response curves not complete within the tested concentration range. Significant agonist responses observed at concentrations of $30 \mu \mathrm{M}$. ${ }^{c}$ Agonist-concentration response curves were biphasic. The compounds elicited significant and concentration-dependent agonist responses at lower concentrations, whereas higher concentrations elicited smaller responses. Significant agonist responses that increased with increasing concentrations were observed for 0.3, 1 and 3 $\mu \mathrm{M}$. At $10 \mu \mathrm{M}$ and higher concentrations, the agonist-induced responses decreased substantially. 
Table $3^{a}$

\begin{tabular}{|c|c|c|c|c|c|c|c|}
\hline & \multicolumn{3}{|c|}{ Binding $\mathrm{K}_{\mathrm{i}}(\mu \mathrm{M})$} & \multicolumn{4}{|c|}{ Functional $(\mu \mathrm{M})$} \\
\hline Compound & $\alpha 4 \beta 2$ & $\alpha 4 \beta 4$ & $\alpha 3 \beta 4$ & $\alpha 4 \beta 2\left(\mathrm{IC}_{50}\right)$ & $\alpha 3 \beta 4\left(\mathrm{IC}_{50}\right)$ & $\alpha 7\left(\mathrm{IC}_{50}\right)$ & $\alpha 7\left(\mathrm{EC}_{50}\right)$ \\
\hline $\mathrm{DH} \beta \mathrm{E}$ & 0.65 & $\sim 25$ & $\sim 100$ & 0.60 & $\sim 100$ & $\sim 100$ & - \\
\hline$(S)-5 c$ & 4.5 & $\sim 100$ & $>100$ & $\sim 30$ & $>100$ & - & weak agonist $^{b}$ \\
\hline$(R)-5 c$ & 0.17 & 6.6 & $\sim 100$ & 1.3 & $>100$ & - & weak agonist $^{C}$ \\
\hline$(S)-\mathbf{5 d}$ & $>100$ & $>100$ & $>100$ & $>100$ & $>100$ & $>100$ & $>100$ \\
\hline$(R)-5 \mathbf{d}$ & 2.5 & $\sim 100$ & $\sim 100$ & 16 & $>100$ & $>100$ & $>100$ \\
\hline$(S)-6 c$ & $\sim 25$ & $\sim 25$ & $\sim 25$ & $>100$ & $>100$ & - & 5.4 \\
\hline$(R)-6 \mathbf{c}$ & 0.045 & 2.7 & 11 & 0.22 & $\sim 50$ & - & 1.6 \\
\hline$(S)-\mathbf{6 d}$ & $\sim 25$ & 7.5 & $\sim 25$ & $>100$ & $>100$ & - & 6.5 \\
\hline$(R)-6 \mathbf{d}$ & 2.4 & $\sim 25$ & $\sim 25$ & 7.2 & $>100$ & - & 5.1 \\
\hline
\end{tabular}

${ }^{a}$ The binding properties of the compounds were determined with membranes from the stable r $\alpha 3 \beta 4-$, r $\alpha 4 \beta 4$ - and r $\alpha 4 \beta 2-$ HEK293 cell lines in a $\left[{ }^{3} \mathrm{H}\right]$ epibatidine binding assay while the functional properties of the compounds were determined

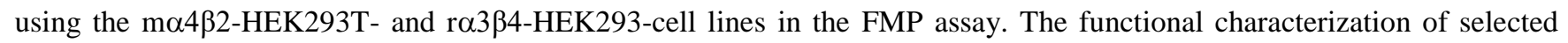
ligands at the human $\alpha 7 \mathrm{nAChR}$ was performed at the stable $h \alpha 7^{\mathrm{Ric}-3 / \mathrm{NACHO}}-\mathrm{HEK} 293$ cell line in the $\mathrm{Ca}^{2+} / \mathrm{Fluo}^{-4}$ assay in the presence of $3 \mu \mathrm{M}$ PNU-120596. The data were the means of 3-5 individual experiments performed in duplicate. The complete data set for this table (i.e., $\mathrm{K}_{\mathrm{i}}\left[\mathrm{pK} \mathrm{K}_{\mathrm{i}} \pm\right.$ S.E.M.] values from the binding experiments, $\mathrm{IC}_{50}$ [pIC $\mathrm{C}_{50} \pm$ S.E.M.], EC 50 [pEC $50 \pm$ S.E.M.] and $\mathrm{R}_{\max } \pm$ S.E.M. values from the functional experiments are given in the Supporting information. ${ }^{b, c}$ Agonist-concentration response curves not complete within the tested concentration range. Significant agonist responses observed at concentrations of $30 \mu \mathrm{M}^{b}$ or $10 \mu \mathrm{M}^{c}$. 
Scheme 1

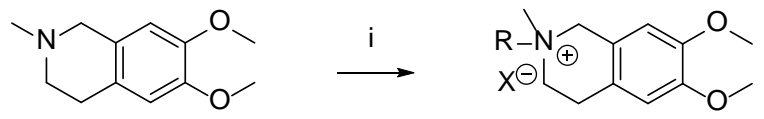

1

R=Methyl, $X=\mathrm{I} \quad$ 2a $R=$ Ethyl, $X=1 \quad$ 2b $\mathrm{R}=n_{\text {-Propyl }} \mathrm{X}=\mathrm{I} \quad$ 2c $\mathrm{R}=\mathrm{Allyl}, \mathrm{X}=\mathrm{Br} \quad$ 2d $\mathrm{R}=\mathrm{Benzy}, \mathrm{X}=\mathrm{Br} \quad \mathbf{2 e}$<smiles>[R]c1cc2c(cc1[R])C([R7])N(C)CC2</smiles>

$\mathrm{R}^{\prime \prime}=\mathrm{H}, \mathrm{R}=\mathrm{OBn}, \mathrm{R}^{\prime}=\mathrm{OCH}_{3} \mathbf{3 a}$ $\mathrm{R}^{\prime \prime}=\mathrm{H}, \mathrm{R}=\mathrm{OCH}_{3}, \mathrm{R}^{\prime}=\mathrm{OBn} \mathbf{3 b}$ $\mathrm{R}^{\prime \prime}=\mathrm{H}, \mathrm{R}=\mathrm{R}=-\mathrm{OCH}_{2} \mathrm{O}-\quad 3 \mathrm{c}$ $\mathrm{R}^{\prime \prime}=\mathrm{dMBn}, \mathrm{R}=\mathrm{R}^{\prime}=\mathrm{OCH}_{3} \quad \mathbf{3 d}$ $\mathrm{R}^{\prime \prime}=\mathrm{H}, \mathrm{R}=\mathrm{OCH}_{3}, \mathrm{R}^{\prime}=\mathrm{OH}$ $\mathrm{R}^{\prime \prime}=\mathrm{H}, \mathrm{R}=\mathrm{OCH}_{3}, \mathrm{R}^{\prime}=\mathrm{H} \quad$ 3f<smiles>[R]c1cc2c(cc1[R])C1CCCN1CC2</smiles>

$\mathrm{R}=\mathrm{OBn}, \mathrm{R}^{\prime}=\mathrm{OCH}_{3} \mathbf{5 a}$ $\mathrm{R}=\mathrm{OCH}_{3}, \mathrm{R}^{\prime}=\mathrm{OBn} \mathbf{5 b}$ $\mathrm{R}=\mathrm{R}^{\prime}=-\mathrm{OCH}_{2} \mathrm{O}-\quad 5 \mathrm{c}$ $\mathrm{R}=\mathrm{R}^{\prime}=\mathrm{OCH}_{3} \quad \mathbf{5 d}$ $\mathrm{R}=\mathrm{H}, \mathrm{R}^{\prime}=\mathrm{OCH}_{3} \quad \mathbf{5 e}$ $\mathrm{R}=\mathrm{OCH}_{3}, \mathrm{R}^{\prime}=\mathrm{H} \quad \mathbf{5 f}$ $\mathrm{R}=\mathrm{R}^{\prime}=\mathrm{H}$

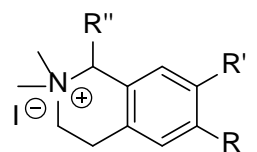

$\mathrm{R}^{\prime \prime}=\mathrm{H}, \mathrm{R}=\mathrm{OBn}, \mathrm{R}^{\prime}=\mathrm{OCH}_{3} \mathbf{4 a}$ $\mathrm{R}^{\prime \prime}=\mathrm{H}, \mathrm{R}=\mathrm{OCH}_{3}, \mathrm{R}^{\prime}=\mathrm{OBn} \mathbf{4 b}$ $\mathrm{R}^{\prime \prime}=\mathrm{H}, \mathrm{R}=\mathrm{R}^{\prime}=-\mathrm{OCH}_{2} \mathrm{O}-\quad \mathbf{4 c}$ $\mathrm{R}^{\prime \prime}=\mathrm{dMBn}, \mathrm{R}=\mathrm{R}^{\prime}=\mathrm{OCH}_{3} \quad \mathbf{4 d}$ $\mathrm{R}^{\prime \prime}=\mathrm{H}, \mathrm{R}=\mathrm{OCH}_{3}, \mathrm{R}^{\prime}=\mathrm{OH} \quad 4 \mathrm{e}$ $\mathrm{R}^{\prime \prime}=\mathrm{H}, \mathrm{R}=\mathrm{OCH}_{3}, \mathrm{R}^{\prime}=\mathrm{H} \quad \mathbf{4 f}$

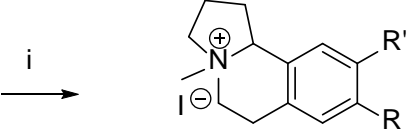

$\mathrm{R}=\mathrm{OBn}, \mathrm{R}^{\prime}=\mathrm{OCH}_{3} \quad \mathbf{6 a}$ $\mathrm{R}=\mathrm{OCH}_{3}, \mathrm{R}^{\prime}=\mathrm{OBn} \quad \mathbf{6 b}$ $\mathrm{R}=\mathrm{R}^{\prime}=-\mathrm{OCH}_{2} \mathrm{O}-\quad \mathbf{6 c}$ $\mathrm{R}=\mathrm{R}^{\prime}=\mathrm{OCH}_{3} \quad \mathbf{6 d}$ $\mathrm{R}=\mathrm{H}, \mathrm{R}^{\prime}=\mathrm{OCH}_{3} \quad \mathbf{6 e}$ $\mathrm{R}=\mathrm{OCH}_{3}, \mathrm{R}^{\prime}=\mathrm{H} \quad \mathbf{6 f}$ $\mathrm{R}=\mathrm{R}^{\prime}=\mathrm{H}$

Scheme 2
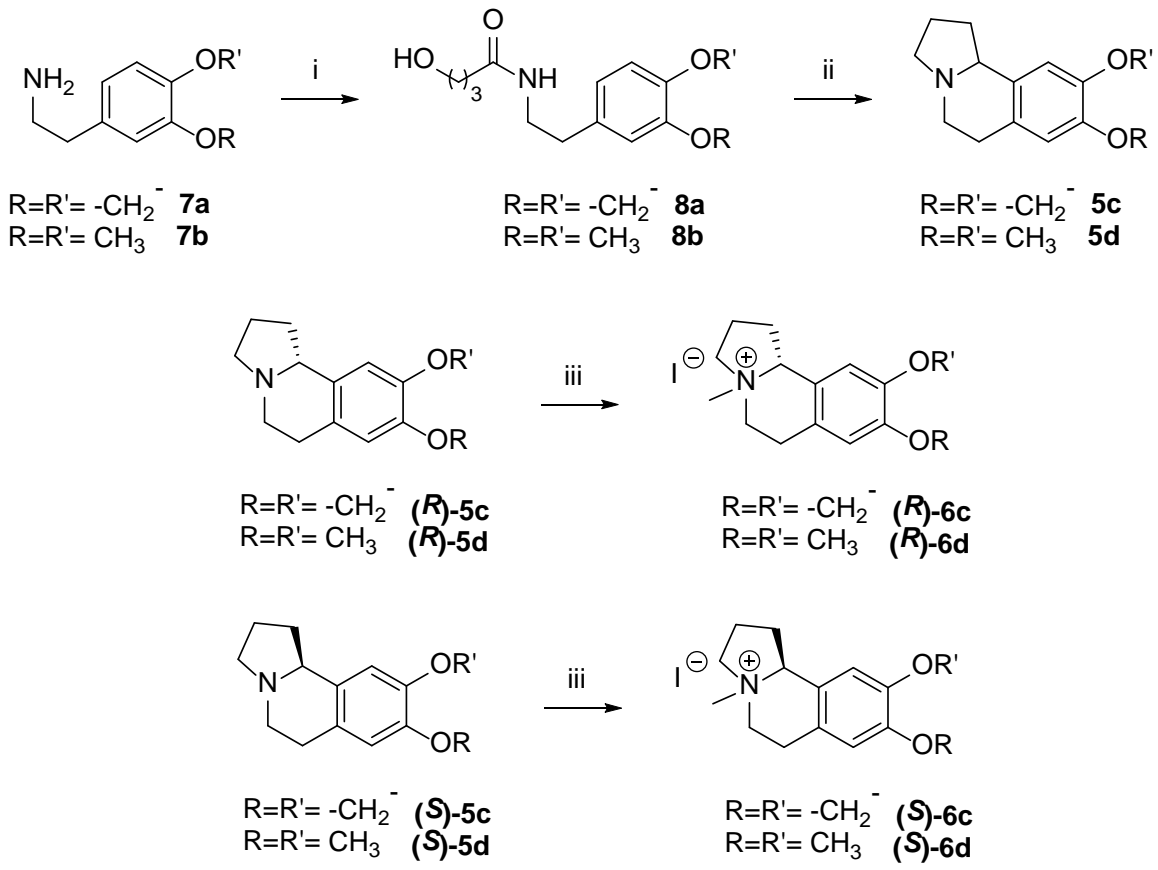
Figure 1

A

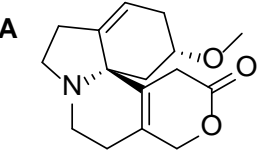

$\mathrm{DH}_{\beta} \mathrm{E}(0.82 \mu \mathrm{M})$

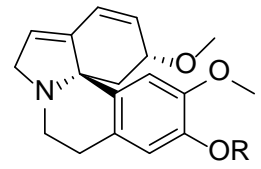

$\mathrm{R}=\mathrm{CH}_{3}$ Erysotrine $(0.60 \mu \mathrm{M})$

$\mathrm{R}=\mathrm{H} \quad$ Erysodine $(0.05 \mu \mathrm{M})$

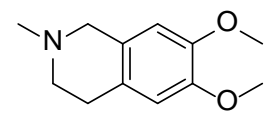

O-Methylcorypalline $(0.87 \mu \mathrm{M})$

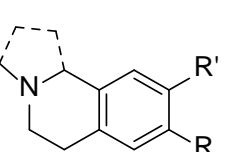

1'3,5

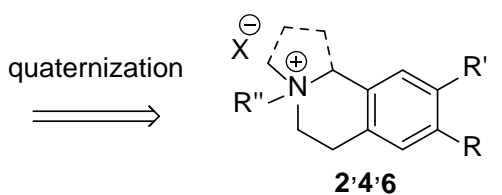


Figure 2

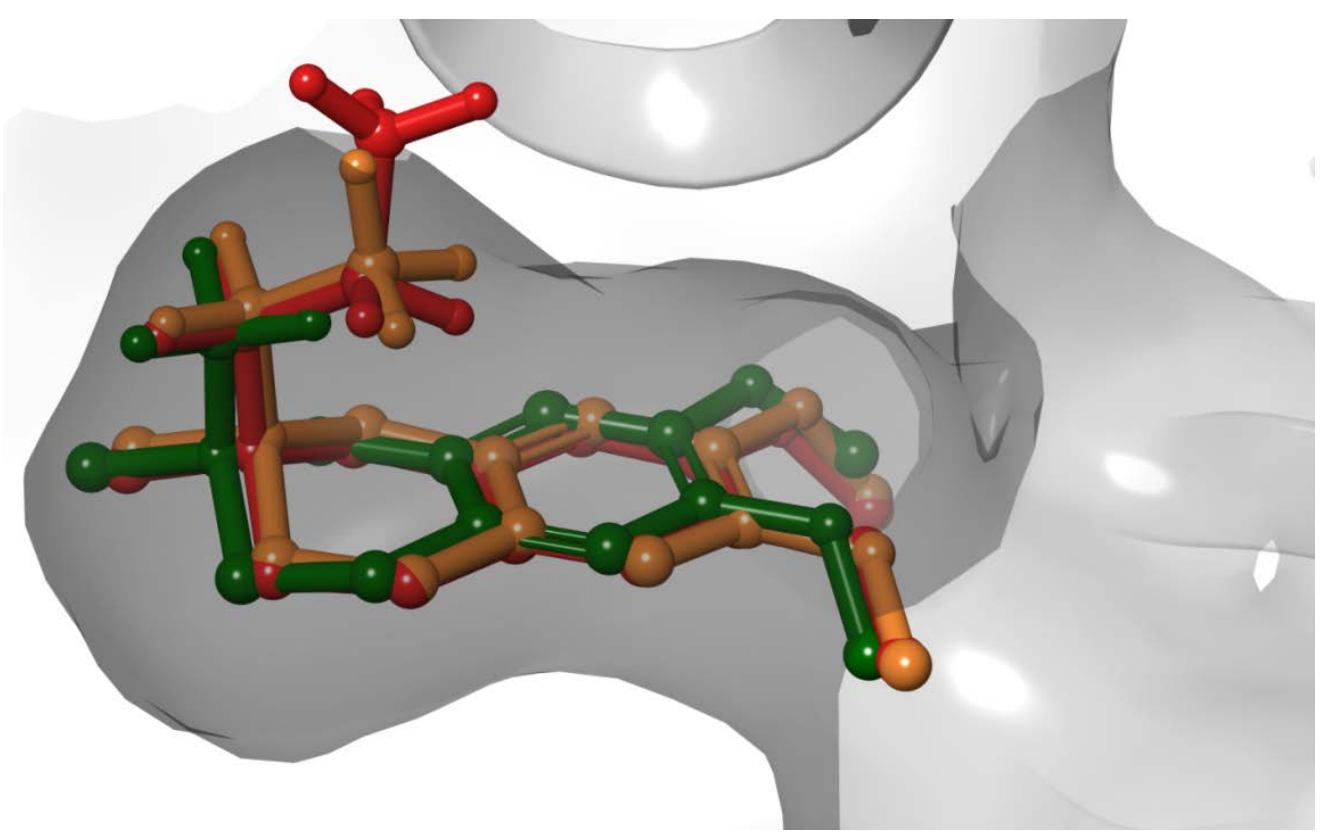


Figure 3
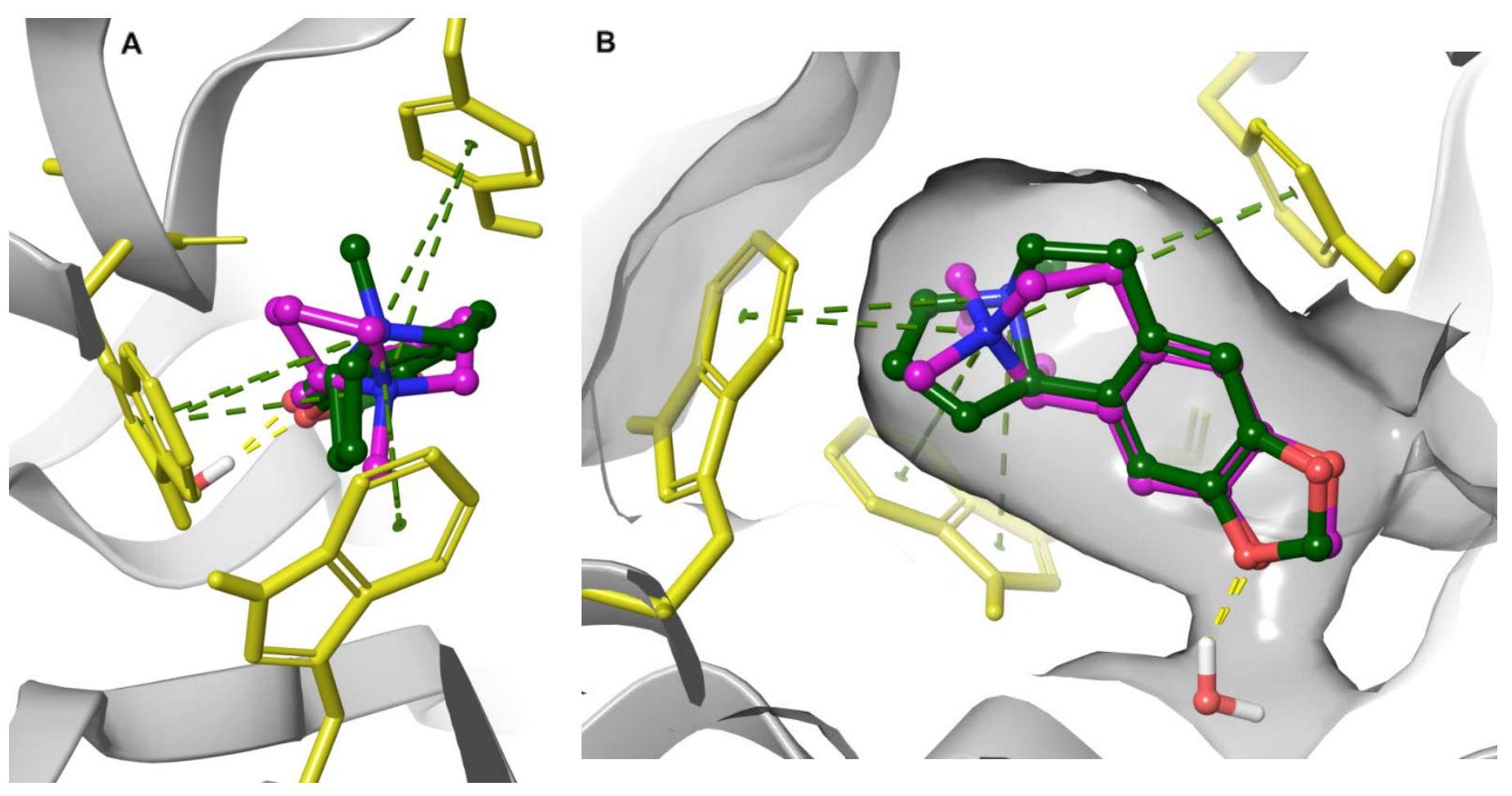
Figure 4

A
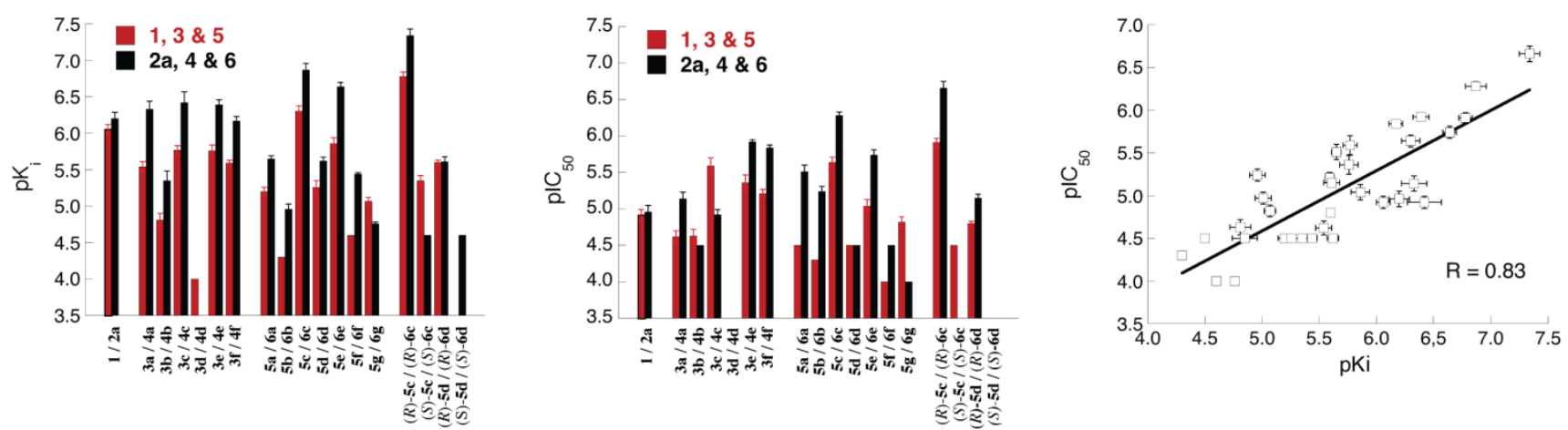

B
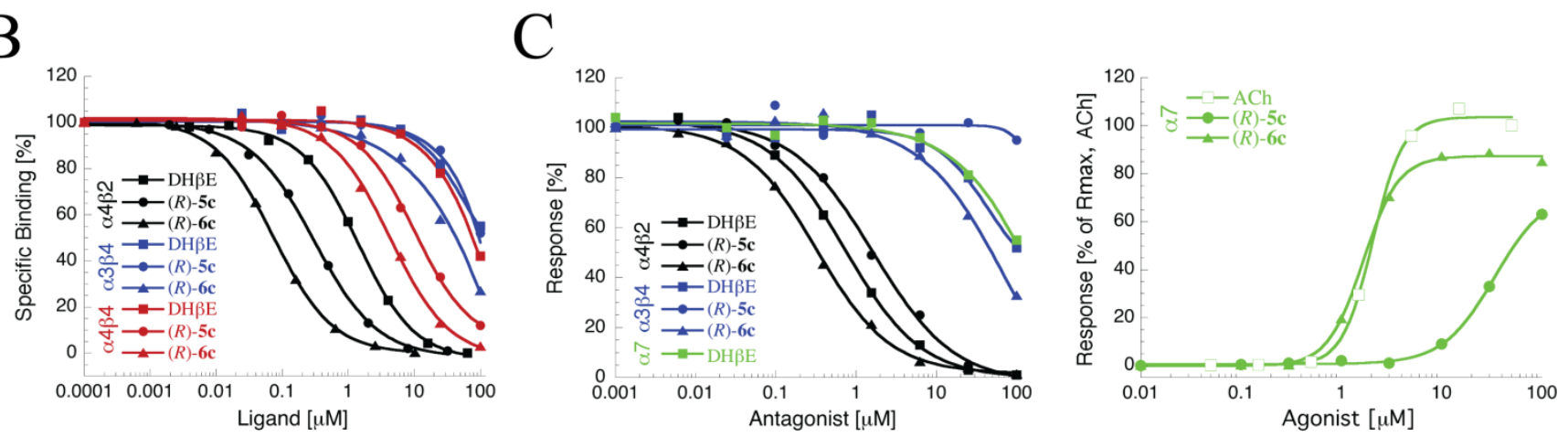
Figure 5
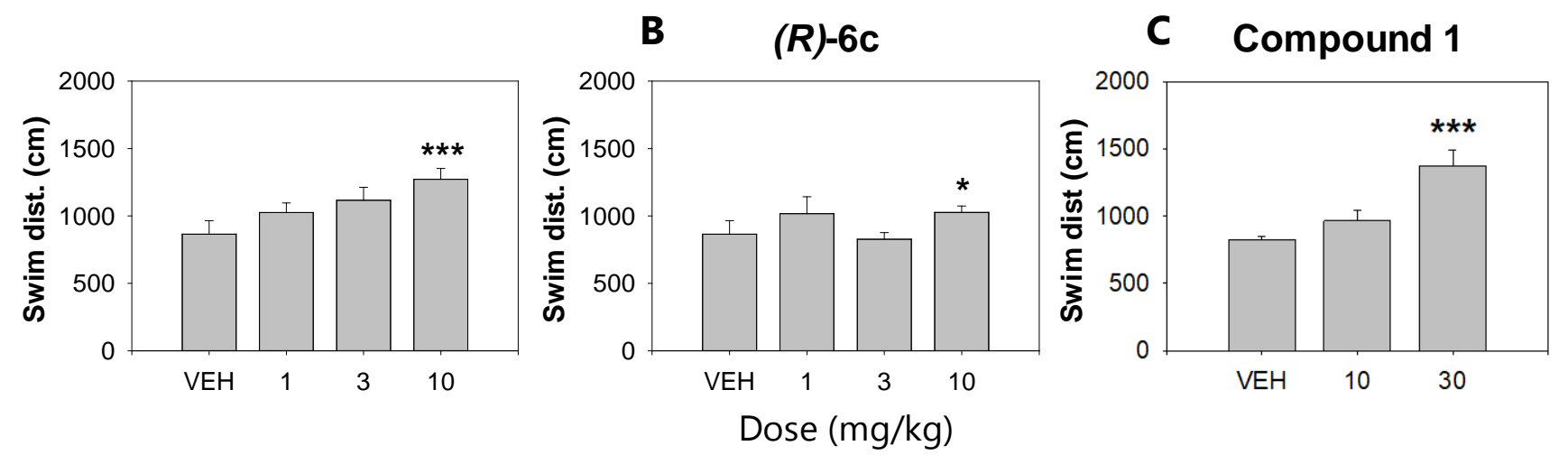


\section{Graphical abstract}

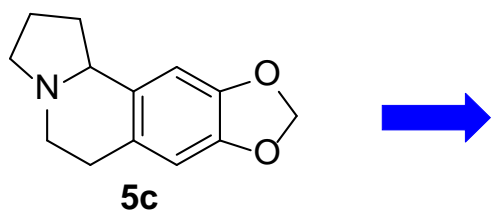

potent ${ }^{\alpha} 4 \beta 2$ antagonist

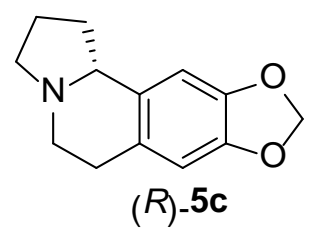

potent $\alpha_{4 \beta 2}$ antagonist and weak ${ }^{\alpha} 7$ agonist

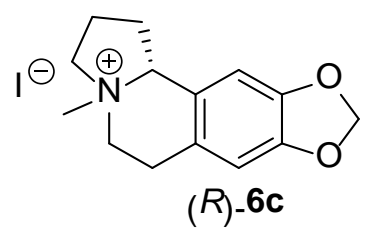

dual potent $\alpha_{4 \beta 2}$ antagonist and $\alpha_{7}$ agonist 